\title{
Photosensitized Oxidative DNA Damage: From Hole Injection to Chemical Product Formation and Strand Cleavage
}

\author{
Byeong Hwa Yun, Young Ae Lee, Seog K. Kim§, Vladimir Kuzmin , Alexander \\ Kolbanovskiy, Peter C. Dedon $\ddagger$, Nicholas E. Geacintov, and Vladimir Shafirovich ${ }^{\star}$ \\ Contribution from the Chemistry Department, New York University, 31 Washington Place, New York, \\ NY 10003-5180
}

\begin{abstract}
Oxidatively generated damage to DNA induced by a pyrenyl photosensitizer residue (Py) covalently attached to a guanine base in the DNA sequence context $5^{\prime}-\mathrm{d}\left(\mathrm{CAT}\left[\mathrm{G}_{1}{ }^{\mathrm{Py}}\right] \mathrm{CG}_{2}\right.$ TCCTAC) in aerated solutions was monitored from the initial one-electron transfer, or hole injection step, to the formation of chemical end-products monitored by HPLC, mass spectrometry, and high-resolution gel electrophoresis. Hole injection into the DNA was initiated by two-photon excitation of the Py residue with $355 \mathrm{~nm}$ laser pulses, thus producing the radical cation $\mathrm{Py}^{\circ+}$ and hydrated electrons; the latter are trapped by $\mathrm{O}_{2}$, thus forming the superoxide anion $\mathrm{O}_{2}{ }^{\cdot-}$. The decay of the $\mathrm{Py}^{*+}$ radical is correlated with the appearance of the $\mathrm{G}^{*} / \mathrm{G}(-\mathrm{H})^{\bullet}$ radical on microsecond time scales, and $\mathrm{O}_{2}{ }^{\cdot-}$ combines with guanine radicals at $\mathrm{G}_{1}$ to form alkali-labile 2,5-diamino- $4 \mathrm{H}$-imidazolone lesions $\left(\mathrm{Iz}_{1} \mathrm{Py}\right)$. Product formation in the modified strand is smaller by a factor of 2.4 in double-stranded than in singlestranded DNA. In double-stranded DNA, hot piperidine-mediated cleavage at $\mathrm{G}_{2}$ occurs only after $\mathrm{G}_{1} \mathrm{Py}$, an efficient hole trap, is oxidized thus generating tandem lesions. An upper limit of hole hopping rates, $k_{\mathrm{hh}}<5 \times 10^{3} \mathrm{~s}^{-1}$ from $\mathrm{G}_{1}{ }^{-+}-\mathrm{Py}$ to $\mathrm{G}_{2}$ can be estimated from the known rates of the combination reaction of the $\mathrm{G}(-\mathrm{H})^{\bullet}$ and $\mathrm{O}_{2}{ }^{\cdot-}$ radicals. The formation of Iz products in the unmodified complementary strand in the duplex is $\sim 10$ times smaller than in the modified strand. The formation of tandem lesions is observed even at low levels of irradiation corresponding to "single-hit" conditions when less than $\sim 10 \%$ of the oligonucleotide strands are damaged. A plausible mechanism for this observation is discussed.
\end{abstract}

\section{Introduction}

In living systems, DNA molecules undergo continuous attack by free radicals, ionizing radiation, environmental pollutants and other damaging agents. These reactions give rise to diverse, potentially mutagenic, oxidative modifications (lesions) of the nucleobases. A significant body of experimental evidence has been accumulated showing that the formation of DNA lesions triggered by one-electron oxidation occurs not only at the DNA bases targeted by the oxidizing species, but also at nucleobases remote from these sites. ${ }^{1-3}$ These effects called DNA chemistry at a distance ${ }^{4}$ have been extensively studied by polyacrylamide gel electrophoresis techniques. ${ }^{1-3}$ In typical experiments, the photoexcitation of a sensitizer positioned at a defined site in DNA duplexes initiates the oxidation of neighboring DNA bases and it is well established that oxidative damage is propagated by a hole transfer mechanism along the DNA helix. ${ }^{1-9}$ The treatment of the irradiated DNA material with hot piperidine or

E-mail: vs5@nyu.edu.

Chemistry Department, Yeongnam University, Gyongsan, Korea 712-749

II Institute of Biochemical Physics, Russian Academy of Sciences, Moscow V-334, Russia

*Biological Engineering Division, Massachusetts Institute of Technology, Cambridge, MA 02139 
base excision repair enzymes induces DNA strand breaks at the sites of the oxidatively modified DNA bases. ${ }^{10}$ The distribution of oxidatively modified bases along the DNA helix is a nonrandom process ${ }^{1-3}$ and occurs with the greatest frequencies at guanine, the most easily oxidizable nucleic acid base. ${ }^{11}$ Damage to other natural DNA bases (A, C and T) is generally significantly less pronounced. More than 70 different DNA lesions have been identified, ${ }^{12}$ including guanine lesions such as, 8-oxo-7,8-dihydro-2'-deoxyguanosine (8-oxodGuo), 2 amino-5-[(2-deoxy- $\beta$-D-erythro-pentofuranosyl)amino]- $4 H$-imidazol-4-one (dIz), 2,2diamino-4-[(2-deoxy- $\beta$-D-erythro-pentofuranosyl) amino]-2,5-dihydrooxazol-5-one (dOz), guanidinohydantoin $(\mathrm{dGh})$ and spiroiminodihydantoin $(\mathrm{dSp})$ nucleosides. All of these lesions are products of the multi-electron oxidation of guanine, and their formation requires formally the abstraction of two (8-oxodGuo) or four electrons (dIz, dOz, dGh and dSp) from the parent guanine. However, investigations of DNA chemistry at a distance have been mostly limited to the analysis of hot piperidine-mediated DNA strand cleavage at the sites of oxidative base damage, and analyzing the distributions of cleavage fragments by polyacrylamide gel electrophoresis. Based on such studies alone, it is not clear how primary one-electron oxidants (holes) injected into DNA by photochemical methods are transformed into the final, multielectron oxidation products of guanine in DNA.

The objectives of this work were to correlate the evolution of radical intermediates and oxidative product formation utilizing a well defined oligonucleotide system with a covalently linked photosensitizer molecule. This arrangement ensures that hole injection occurs at a defined site, and eliminates the questions associated with the primary one-electron oxidation step when solution-borne one-electron oxidants are used to oxidize individual nucleotides in DNA. As a photosensitizer, we selected a pyrenyl (Py) residue attached covalently to a guanine $\left(\mathrm{G}^{\mathrm{Py}}\right)$ embedded either in a single- or a double-stranded oligonucleotide. The aromatic Py ring system absorbs light at $355 \mathrm{~nm}$, well outside of the DNA absorption band. The latter was derived from the binding of a racemic anti-BPDE (7r,8t-dihydroxy- $t 9,10$-epoxy-7,8,9,10tetrahydrobenzo[a]pyrene) to the target guanine, $\mathrm{G}_{1}$, in the sequence $5^{\prime}$-d(CAT[ $\left.\mathbf{G}_{\mathbf{1}} \mathbf{P y}^{\mathbf{P y}}\right]$ $\mathbf{C G}_{\mathbf{2}}$ TCCTAC) shown in Figure 1 .

In such sequence contexts, ${ }^{13,14}$ the aromatic pyrene-like ring system is positioned in the minor groove and points toward the $5^{\prime}$-end of the modified strand. Photoexcitation of this oligonucleotide with intense $355 \mathrm{~nm}$ nanosecond laser pulses induces efficient two-photon ionization of the Py residues, thus yielding pyrenyl-like aromatic radical cations $\left(\mathrm{Py}^{\circ+}\right)$ that oxidize the guanine residues to which they are attached, thus injecting holes into the sequence. This model system, involving intramolecular electron transfer events, allowed us to monitor the fates of the primary radical intermediates, and the identification and evolution of the chemical products. The time course of oxidized guanine product formation was followed by HPLC methods and was compared to strand cleavage monitored by hot-alkali induced strand scission followed by analysis using gel electrophoresis methods. This approach allowed us to evaluate relationships between oxidatively generated damage at $\mathrm{G}_{1} \mathrm{Py}$ and $\mathrm{G}_{2}$ in the modified strand, and guanines $\mathrm{G}_{3-7}$ in the complementary strand.

\section{Experimental Section}

\section{Materials}

All chemicals (analytical grade) were used as received. Snake venom phosphodiesterase was purchased from Pharmacia (Piscataway, NJ); calf spleen phosphodiesterase, nuclease P1 and alkaline phosphatase were from Sigma Chemical (St. Louis, MO), Cu,Zn-superoxide dismutase was from Roche Applied Science (Indianapolis, IN). The oligonucleotides were purchased from Integrated DNA Technologies (Coralville, IA) and purified by reversed-phase HPLC. The modified 12-mer oligonucleotide 5'-d(CAT[ $\left.\mathbf{G}_{\mathbf{1}}{ }^{\mathbf{P y}}\right] \mathbf{C G}_{\mathbf{2}}$ TCCTAC) was prepared by direct reaction of racemic anti-BPDE (a gift from Dr. S. Amin, American Health 
Foundation, Valhalla, NY) with the unmodified oligonucleotide and the products were separated and purified by reversed phase HPLC methods as previously described. ${ }^{15,16}$. The site-specifically modified oligonucleotide containing the $10 S(+)$-trans-anti-[Py]- $N^{2}$-dG adduct was used in all further experiments (Figure 1). The integrity and position of the Py lesion at the $\mathrm{G}_{1}$ site was confirmed by enzymatic sequencing of the modified oligonucleotide followed by the MALDI-TOF/MS analysis as described earlier. ${ }^{16}$ The authentic 8oxodGuo $^{\mathrm{Py}}$ adducts were also synthesized by the direct reaction of racemic anti-BPDE with 8-oxo-7,8-dihydro-2'-deoxyguanosine. Four stereoisomeric adducts, (+)-trans-anti-[Py]$N^{2}$-8-oxodGuo, (-)-trans-anti-[Py]- $N^{2}-8$-oxodGuo, (+)-cis-anti-[Py]- $N^{2}-8$-oxodGuo and (-)cis-anti-[Py]- $N^{2}-8$-oxodGuo were isolated by reversed-phase HPLC and identified via their circular dichroism (CD) spectra as described in Supporting Information (Figures S1 and S2). The chemical structure of the synthesized adducts was confirmed by ESI-MS techniques.

\section{Laser Flash Photolysis}

The kinetics of free radical reactions were monitored in real time utilizing transient absorption spectroscopy techniques. The fully-computerized kinetic spectrometer system $(\sim 7 \mathrm{~ns}$ response time) used for this purpose was described elsewhere. ${ }^{17}$ Briefly, $355 \mathrm{~nm}$ nanosecond Nd:Yag laser pulses were used to photolyse the sample solutions $(0.25 \mathrm{~mL})$ contained in a $0.4 \times 1 \mathrm{~cm}$ quartz cell. The concentrations of $5^{\prime}-\mathrm{d}\left(\mathrm{CAT}\left[\mathbf{G}_{\mathbf{1}}{ }^{\mathbf{P y}}\right] \mathbf{C G}_{\mathbf{2}}\right.$ TCCTAC) in phosphate buffer solutions ( $\mathrm{pH} 7$ ) were generally $\sim 10 \mu \mathrm{M}$ (the concentration was estimated from the molar extinction coefficient ${ }^{18}$ of the aromatic Py residue, $\varepsilon_{350}=2.4 \times 10^{4} \mathrm{M}^{-1} \mathrm{~cm}^{-1}$ ). The transient absorbance was probed at right angle to the excitation laser beam along a $1 \mathrm{~cm}$ optical path by a light beam from a $75 \mathrm{~W}$ xenon arc lamp triggered to provide an enhanced-intensity light pulse on the millisecond time scale. The signal was recorded by a Tektronix TDS 5052 oscilloscope operating in its high resolution mode that typically allows for a suitable signal/noise ratio after a single laser shot. Rate constants were determined by least squares fits of the appropriate kinetic equations to the kinetic curves obtained in five independent experiments with five different samples.

\section{HPLC Purification}

After the irradiation experiments, the modified oligonucleotides were separated from the unmodified ones by reversed-phase HPLC using an analytical $(250 \times 4.6 \mathrm{~mm}$ i.d.) MicrosorbMV C18 column (Varian, Walnut Creek, CA). In typical separations, a 10-30\% linear gradient of acetonitrile in $50 \mathrm{mM}$ triethylammonium acetate in water $(\mathrm{pH} 7)$ for 60 min was employed at a flow rate of $1 \mathrm{~mL} / \mathrm{min}$ (detection of products at $260 \mathrm{~nm}$ ). The HPLC fractions were evaporated under vacuum to remove acetonitrile and were purified by a second HPLC cycle. The purified adducts were desalted by reversed-phase HPLC using the following mobile phases: $5 \mathrm{mM}$ ammonium acetate (10 $\mathrm{min})$, deionized water (10 $\mathrm{min})$, and an isocratic $50: 50$ acetonitrile and $\mathrm{H}_{2} \mathrm{O}$ mixture (15 min) and subjected to MALDI-TOF/MS analysis.

\section{MALDI-TOF/MS Assay of Oligonucleotides}

The mass spectra were acquired using a Bruker OmniFLEX instrument. The matrix was a 2:1 mixture of 2',4',6'-trihydroxyacetophenone methanol solution $(30 \mathrm{mg} / \mathrm{mL})$ and ammonium citrate aqueous solution $(100 \mathrm{mg} / \mathrm{mL})$. The aliquots $(1-2 \mu \mathrm{L})$ of the $10 \mathrm{pmol} / \mu \mathrm{L}$ desalted samples and the matrix solution were spotted on a MALDI target and air-dried before analysis. The mass spectrometer equipped with a $337 \mathrm{~nm}$ nitrogen laser was operated in the negative linear mode (accelerating voltage $19 \mathrm{kV}$, extraction voltage $92.7 \%$ of the accelerating voltage, ion focus $9 \mathrm{kV}$, and delay time $250 \mathrm{~ns}$ ). Each spectrum was obtained with an average of $50-$ 300 laser shots. The mass spectra were internally calibrated by using synthetic oligonucleotides of known molecular weights. 


\section{Isolation of the M+16 Lesions}

Calf spleen phosphodiesterase (0.004 units) in $100 \mu \mathrm{L} 20 \mathrm{mM}$ succinic acid buffer (pH 6) containing $10 \mathrm{mM} \mathrm{CaCl}_{2}$ and nuclease $\mathrm{P} 1$ ( 2 units) in $35 \mu \mathrm{L}$ of $30 \mathrm{mM}$ acetate buffer (pH 5.2) were added to the intact irradiated oligonucleotide $(5 \mathrm{nmol})$ that was characterized by mass $\mathrm{M}$ +16 where $\mathrm{M}$ is the mass of the unirradiated, anti-BPDE-modified oligonucleotide with the lesion at $\mathrm{G}_{1}$. These digestion mixtures were incubated at $37^{\circ} \mathrm{C}$ for $2 \mathrm{~h}$, Subsequently, snake venom phosphodiesterase ( 0.003 units) in $1 \mu \mathrm{L}$ of $110 \mathrm{mM}$ Tris- $\mathrm{HCl}$ buffer solution (pH 8.9) containing $110 \mathrm{mM} \mathrm{NaCl}$ and $15 \mathrm{mM} \mathrm{MgCl} 2$ and alkaline phosphatase (5 units) in $17 \mu \mathrm{L} 500$ $\mathrm{mM}$ Tris- $\mathrm{HCl}$ buffer solution ( $\mathrm{pH} 8.5$ ) were added and the digestion mixtures were continued at $37^{\circ} \mathrm{C}$ for another $2 \mathrm{~h}$ period. The digestion mixtures were then passed through a Millipore centrifugal filter to remove the enzymes. The nucleosides were separated by reversed-phase HPLC using a $0-90 \%$ linear gradient of methanol in $50 \mathrm{mM}$ ammonium acetate at a flow rate of $1 \mathrm{~mL} / \mathrm{min}$ and subjected to LC-MS/MS analysis.

\section{LC-MS/MS Assay of Nucleosides}

These experiments were performed using an LC/MSD-trap XCT spectrometer (Agilent Technologies, Palo Alto, CA) with an Agilent 1100 Series Capillary LC System. The $10 \mathrm{pmol} /$ $\mu \mathrm{L}$ desalted samples in 70:30 MeCN : water solutions containing $0.1 \%$ formic acid were infused at a $10 \mu \mathrm{L} / \mathrm{min}$ flow rate. The mass spectra were recorded in the positive mode. The spectrometer was tuned to maximum sensitivity by the direct infusion of the authentic nucleoside standard solutions. The nebulizer gas pressure was $40 \mathrm{psi}$, the dry gas flow rate was $8.0 \mathrm{~L} / \mathrm{min}$, and the dry temperature was set at $350{ }^{\circ} \mathrm{C}$. For general analytical experiments, the instrument was operated using the "smart" parameter setting and the detector was set for a particular ion of interest. Mass spectra were obtained by averaging over the area of a particular total ion chromatogram peak and the background intensity was then subtracted. In the manual tandem mass mode, the target molecular mass was the mass of the highest intensity fraction obtained in the previous scan.

\section{Amperometric Analysis of Nucleosides}

The nucleosides derived from the enzymatic digestion of the photooxidized oligonucleotides were separated by reversed-phase HPLC using a $0-90 \%$ linear gradient of methanol in 50 $\mathrm{mM}$ ammonium acetate $(\mathrm{pH}$ 5.2) for $1 \mathrm{~h}$ at a flow rate of $1 \mathrm{~mL} / \mathrm{min}$ and detected by employing a Model 800A electrochemical analyzer (CHI Instruments, Austin, TX). The potential of the glassy carbon working electrode was set at $0.6 \mathrm{~V}$ vs $\mathrm{Ag} / \mathrm{AgCl}$ electrode, as suggested for the detection of 8-oxodGuo. 19,20 The instrument was calibrated by injecting known quantities of 8-oxodGuo and [Py]- $N^{2}-8$-oxodGuo.

\section{Photodamage of the DNA Duplexes and Oxidative DNA Strand Cleavage Assay}

The preparation of $5^{\prime}$ - and $3^{\prime}$-endlabeled ${ }^{32} \mathrm{P}$-endlabeled DNA sequences followed the standard protocols as described in Supporting information. The $10 \mu \mathrm{L}$ samples of the duplexes $(\sim 5$ $\mu \mathrm{M})$ containing ${ }^{32} \mathrm{P} 5^{\prime}$ - or $3^{\prime}$-end labeled strands in $2 \times 2 \mathrm{~mm}$ square pyrex capillary tubes (Vitrocom, Inc., Mountain Lakes, NJ) were irradiated with $355 \mathrm{~nm}$ nanosecond Nd:YAG laser pulses using a computer-interfaced electromechanical shutter to control the irradiation time. To reveal oxidatively modified DNA bases, the irradiated samples were treated with hot piperidine that induces strand breaks at the sites of modification as described in more detail in Supporting Information. The vacuum dried gels were quantitatively assayed using a Storm 840 Phosphorimage System (GE Healthcare). The ratios of the sum of the intensities of the DNA hot piperidine-mediated cleavage patterns per total integral intensity calculated from the histograms obtained by scanning the original autoradiograms, were used to estimate the efficiencies of DNA cleavage. The efficiencies of DNA photocleavage reported in this paper are the average results obtained in 3 independent experiments. 


\section{Results}

The objectives of this work were to explore the pathways of oxidation of guanine residues in oligonucleotides photosensitized by a pyrenyl residue attached covalently to guanine in DNA. 18,21 Specifically, the objectives were to investigate the relationships between the photochemically induced damage at $\mathrm{G}_{1}{ }^{\mathrm{Py}}$, the modified guanine, and at $\mathrm{G}_{2}$, a nearby unmodified guanine residue, with product formation measured by mass spectrometry methods and hot alkali-induced cleavage of damaged guanines at the same sites. In these experiments, the pyrenyl residue positioned at $\mathrm{G}_{1}$ is photoionized by a two-photon excitation mechanism, and the resulting pyrenyl radical cation oxidizes the guanine residue $\left(\mathrm{G}_{1}\right)$ to which it is attached, by a one-electron transfer mechanism, thus injecting a "hole" into the sequence 5 '-d(CAT $\left[\mathbf{G}_{\mathbf{1}} \mathbf{P y}_{\mathbf{C}} \mathbf{C G}_{\mathbf{2}}\right.$ TCCTAC). Following laser pulse excitation, this initial and key electron transfer step, and the subsequent radical-radical combination reactions that ultimately culminate in the formation of the oxidative DNA end-products, are monitored by transient absorption spectroscopy. Finally, the major products of the reaction are identified by analytical methods and the distributions of alkali-labile DNA lesions are obtained by polyacrylamide gel electrophoresis.

The experiments were performed with the oligonucleotide, $5^{\prime}-\mathrm{d}\left(\mathrm{CAT}\left[\mathbf{G}_{\mathbf{1}} \mathbf{P y}_{\mathbf{y}}\right] \mathbf{C G}_{\mathbf{2}}\right.$ TCCTAC) either in the single-stranded or in the double-stranded form (Figure 1). This oligonucleotide strand contained the $10 S(+)$-trans-anti-[Py]- $N^{2}$-dG adduct (Figure 1) at the position $\mathrm{G}_{1}$, separated from the second guanine $\mathrm{G}_{2}$ by one $\mathrm{C}$ base. The duplexes were prepared by annealing the Py-modified strand with its natural complementary strand in $5 \mathrm{mM}$ phosphate buffer solution (pH 7.5) containing $100 \mathrm{mM} \mathrm{NaCl}$. Studies with single- and double-stranded oligonucleotides were performed at room temperature $\left(23 \pm 2^{\circ} \mathrm{C}\right)$.

\section{Kinetics of $\mathrm{G}(-\mathrm{H})^{\bullet}$ Radicals in DNA}

Typical transient absorption spectra of $5^{\prime}$-d $\left(\mathrm{CAT}\left[\mathbf{G}_{\mathbf{1}}{ }^{\mathbf{P y}}\right] \mathrm{CG}_{\mathbf{2}}\right.$ TCCTAC) recorded at various delay times $(\Delta t)$ after the laser pulse excitation are shown in Figure 2A. The spectrum recorded after $\Delta t=0.1 \mu$ s is characterized by a bleaching of the Py ground state absorption bands at 320 and $355 \mathrm{~nm}$, and the appearance of new absorption bands at 315, 455 and $670 \mathrm{~nm}$.

In agreement with previous observations, ${ }^{18,21,22}$ the $455 \mathrm{~nm}$ band is assigned to the Py*+ radical cation, a shoulder near $420 \mathrm{~nm}$ is attributed to the Py triplet excited state $\left({ }^{3} \mathrm{Py}\right)$, and the broad band near $670 \mathrm{~nm}$ is due to hydrated electrons that arise from the two-photon photoionization of the Py residues. The unmodified nucleic acid bases (A, C, G and T) do not react chemically with ${ }^{3} \mathrm{Py}$ which is rapidly converted to the ground state by molecular oxygen (within $\sim 2.5 \mu \mathrm{s}$ ). ${ }^{21}$ The yield of hydrated electrons, $e_{\mathrm{aq}}{ }^{-}$estimated from their absorbance at $700 \mathrm{~nm}\left(\varepsilon=1.9 \times 10^{4} \mathrm{M}^{-1} \mathrm{~cm}^{-1,23}\right)$ is greater by a factor of $\sim 1.6$ than the yield of Py ${ }^{\circ+}$ radicals calculated from their absorbance at $455 \mathrm{~nm}\left(\varepsilon=3 \times 10^{4} \mathrm{M}^{-1} \mathrm{~cm}^{-1,18}\right)$. These estimates show that a significant fraction of $\mathrm{Py}^{-+}$radicals $(30-40 \%)$ decay within the initial time interval $(0$ $-100 \mathrm{~ns}$ ) after the laser flash. This rapid decay of Py ${ }^{\circ+}$ radicals, which could not be resolved by our experimental apparatus, is accompanied by the prompt formation of guanine radicals within $0-100 \mathrm{~ns}$ after the laser flash; the guanine radicals are characterized by an absorption maximum at $315 \mathrm{~nm} .{ }^{11,17,24-27}$ The narrow band near $315 \mathrm{~nm}$ recorded at $\Delta t \geq 0.4 \mu$ s can be assigned to the guanine neutral radical, $\mathrm{G}(-\mathrm{H})^{\bullet}$, derived from the deprotonation of $\mathrm{G}^{\circ+}$ radical cations (Figure 2 ) that occurs within $\sim 0.3 \mu$ s in DNA. 28

In air-equilibrated solutions, the decay of the hydrated electrons monitored at $650 \mathrm{~nm}$ is extremely fast and occurs with the pseudo-first order rate constant $k_{1}=5.7 \times 10^{6} \mathrm{~s}^{-1}$ (data not shown). The second order rate constant $\left(2.2 \times 10^{10} \mathrm{M}^{-1} \mathrm{~s}^{-1}\right)$ for reaction of $e^{-}$aq and $\mathrm{O}_{2}$ calculated from this $k_{1}$ value and $\left[\mathrm{O}_{2}\right]=0.26 \mathrm{mM}$ in air-equilibrated solutions is in good agreement with the diffusion-controlled literature value $\left(1.9 \times 10^{10} \mathrm{M}^{-1} \mathrm{~s}^{-1}, 23\right)$. Hydrated 
electrons have a very broad absorption spectrum and contribute to the absorption of the Py*+ radicals at $455 \mathrm{~nm}$. For this reason, the decay of the transient absorbance at $455 \mathrm{~nm}$ (Figure 2B) was approximated by a multi-exponential kinetic model. We found that a three-exponential model $\left[A_{t} / A_{0}=a_{1} \exp \left(-k_{1} t\right)+a_{2} \exp \left(-k_{2} t\right)+a_{3} \exp \left(-k_{3} t\right)+b\right]$ provides the best fit to the transient $455 \mathrm{~nm}$ decay profiles with the following parameters, $k_{1}=5.7 \times 10^{6} \mathrm{~s}^{-1}\left(a_{1}=0.23\right)$, $k_{2}=4.1 \times 10^{6} \mathrm{~s}^{-1}\left(a_{2}=0.48\right)$, and $k_{3}=3.0 \times 10^{5} \mathrm{~s}^{-1}\left(a_{3}=0.18\right)$. The value of $k_{1}$ is in a good agreement with the rate constant of the $e^{-}$aq decay measured at $650 \mathrm{~nm}$, and the third Py ${ }^{\circ+}$ kinetic component $\left(k_{3}\right)$ is correlated with the kinetics of formation of the $\mathrm{G}(-\mathrm{H})^{\bullet}$ radicals (Figure 2B). The appearance of the guanine radicals monitored at $315 \mathrm{~nm}$ (Figure 2B) is described by first-order kinetics $\left[A_{t} / A_{0}=1-a_{4} \exp \left(-k_{4} t\right)\right]$ with the rate constant $k_{4}=3.0 \times 10^{5} \mathrm{~s}^{-1}\left(a_{4}=\right.$ 0.40 ); this constant has the same value as $k_{3}$ assigned to the $\mathrm{Py}^{\bullet+}$ decay at $455 \mathrm{~nm}$. The origin of the second $\mathrm{Py}^{\bullet+}$ decay component $\left(k_{2}\right)$ is attributed to other, unspecified reactions. In summary, the decay of the $\mathrm{Py}^{\circ+}$ radicals occurs via multiple pathways and the complete decay of the $\mathrm{Py}^{\circ+}$ absorbance at $455 \mathrm{~nm}$ does not fully regenerate the Py ground state absorbance bands at 320 and $355 \mathrm{~nm}$. Some of the $\mathrm{Py}^{\circ+}$ radicals give rise to the formation of unidentified long-lived intermediates that are characterized by the changes in absorption of the pyrenyl ring system reported by this laboratory earlier. ${ }^{21}$

The $\mathrm{G}(-\mathrm{H})^{\bullet}$ radicals derived from the oxidation of $\mathrm{G}$ by the photoionized $\mathrm{Py}^{\bullet+}$ radicals decay on a millisecond time scale $(\leq 40 \mathrm{~ms})$ as shown in Figure 3C. One of the major reaction partners of the $\mathrm{G}(-\mathrm{H})^{\bullet}$ radicals is the superoxide radical that is formed by the trapping of hydrated electrons by dissolved oxygen. At $\mathrm{pH} 7.5$, the disproportionation reaction of $\mathrm{O}_{2}{ }^{--}$radicals is relatively slow (bimolecular rate constant: $5.2 \times 10^{5} \mathrm{M}^{-1} \mathrm{~s}^{-129}$ ), and the combination of the $\mathrm{G}$ $(-\mathrm{H})^{\circ}$ and $\mathrm{O}_{2}{ }^{-}$radicals becomes the major pathway for decay of these radicals. ${ }^{30}$ The kinetics and end-products of this reaction are discussed below.

\section{Chemical End-products Arising from the Decay of G(-H) ${ }^{\bullet}$ Radicals}

Damage of the single-stranded 5'-d(CAT[ $\left.\mathbf{G}_{\mathbf{1}}{ }^{\mathbf{P y}}\right] \mathrm{CG}_{\mathbf{2}}$ TCCTAC) sequence initiated by intense $355 \mathrm{~nm}$ laser pulse excitation in air-equilibrated solutions ( $\mathrm{pH} 7.5)$ was monitored by reversedphase HPLC methods (Figure 3A). At laser pulse energies of $\sim 35-40 \mathrm{~mJ} / \mathrm{cm}^{2}$ used in singleshot transient absorption experiments, the observed photooxidative DNA damage is too extensive and too rapid for monitoring the kinetics of product formation by HPLC methods, and a broad background of unspecified products is observed at long irradiation times or high pulse energies (Figure S3). Therefore, a lower laser pulse energy $\left(4 \mathrm{~mJ} / \mathrm{cm}^{2}\right)$ was employed to initiate DNA damage at a more convenient, lower rate (Figure 4). We found that the same principal end-products of oxidative DNA damage are obtained at the higher as well as at the lower laser pulse energies (data not shown).

A typical reversed-phase HPLC elution profile of the single-stranded oligonucleotide solution irradiated under these conditions is depicted in Figure 3A. The unmodified oligonucleotide elutes at $28 \mathrm{~min}$ and three prominent reaction products are detected that elute at 22, 24 and 26 $\mathrm{min}$. The latter fractions were collected after multiple HPLC injections, combined, purified by second HPLC runs, desalted, and subjected to MALDI-TOF/MS analysis.

The MALDI-TOF mass spectrum of the 26 min fraction recorded in the negative mode (Figure S4 in Supporting Information) exhibits a major signal at $\mathrm{m} / 23843.7$ (M-39) and two additional signals at $\mathrm{m} / z 3541.7$ (M-341) and $\mathrm{m} / z 3447.7$ (M-435), whereas the unmodified sequence (Figure S5) exhibits a signal at $\mathrm{m} / \mathrm{z} 3882.7$ (M). The major signal with a mass of M-39 was assigned to the adduct containing the imidazolone lesion 31,32 that retains the covalently attached Py residue, $5^{\prime}-\mathrm{d}\left(\mathrm{CAT}\left[\mathbf{I z}_{\mathbf{1}} \mathbf{P y}_{\mathbf{1}}\right] \mathbf{C G}_{\mathbf{2}}\right.$ TCCTAC). The additional signals in the mass spectrum of this sample were assigned to the Iz lesions, but without the Py residue, $5^{\prime}$-d(CAT $\left[\mathbf{I z}_{\mathbf{1}}\right] \mathbf{C G}_{\mathbf{2}}$ TCCTAC) (M-342) and the abasic sequence, 5'-d(CAT_CG $\mathbf{C}_{2}$ TCCTAC) (M-436) derived from the fragmentation of the parent $5^{\prime}-\mathrm{d}\left(\mathbf{C A T}\left[\mathbf{I z}_{\mathbf{1}}{ }^{\mathbf{P y}}\right] \mathbf{C G}_{\mathbf{2}}\right.$ TCCTAC) sequence 
induced by the intense UV laser pulses that volatilize the sample in the MALDI-TOF mass spectrometer. This conclusion is supported by the observation that the abasic sequence was not present in the original 5'-d(CAT[Iz $\left.{ }_{1}{ }^{\mathbf{P y}}\right] \mathbf{C G}_{2}$ TCCTAC) sample subjected to MALDI-TOF analysis: it would have been easily detected during the HPLC purification and the isolation step of the d(CAT[ $\left.\mathbf{I z}_{1}{ }^{\text {Py }}\right] \mathbf{C G}_{2}$ TCCTAC) sequence. In agreement with previous observations, $30^{-} 32$ the Iz moiety in the $5^{\prime}-\mathrm{d}\left(\mathrm{CAT}\left[\mathbf{I z}_{1}{ }^{\mathbf{P y}}\right] \mathbf{C G}_{2}\right.$ TCCTAC) adduct is unstable and slowly decomposes in neutral solutions at room temperature to form the Py-modified oxazolone derivative. The 5'-d(CAT[Oz $\left.{ }_{1}^{\mathbf{P y}}\right] \mathbf{C G}_{2}$ TCCTAC) sequence containing the Py-modified Oz residue was identified by the MS signal at $m / z 3861.7$ (M-21), and the decarboxylated oxazolone adduct at $\mathrm{m} / \mathrm{z} 3817.7$ (M-65) that arises from the fragmentation of the oxazolone $^{33}$ during the course of the MS analysis (inset in Figure S4). The integrity of the Iz oligonucleotide sequences and the site of modification at $\mathrm{Iz}_{1}$ were confirmed by MALDI-TOF/ MS analysis of the exonuclease digestion ladders (see, Figure S6 in Supporting Information). Thus, in the presence of $\mathrm{O}_{2}^{\bullet-}$ radicals, the Py-modified $\mathrm{G}(-\mathrm{H})^{\bullet}$ radicals are transformed to the Py-modified $\mathrm{Iz}^{\mathrm{Py}}$ and $\mathrm{Oz}{ }^{\mathrm{Py}}$ products in a manner characteristic of unmodified $\mathrm{G}(-\mathrm{H})^{\bullet}$ radicals generated by other methods. 30

The MALDI-TOF mass spectra of the 22 and 24 min fractions ( 1 and 2 in Figure 3A) recorded in the negative mode, exhibit the same signal at $m / z 3898.7(\mathrm{M}+16)$ (see, Figure $\mathrm{S} 7$ in Supporting Information). The integrity of the M+16 oligonucleotide sequences and the site of modification at $\mathrm{G}_{1}$ were confirmed by MALDI-TOF/MS analysis of the exonuclease digestion ladders (see, Figure S8 in Supporting Information). The modified and oxidized $\mathrm{G}_{1} \mathrm{Py}_{\text {residue }}$ in the major M+16 oligonucleotide sequence (fraction 1 in Figure 3) is not hot alkali-labile, i.e., it is not cleaved under conditions that cleave the modified oligonucleotides at the $\mathrm{Iz}^{\mathrm{Py}}$ or $\mathrm{Oz}^{\mathrm{Py}}$ lesions at the same site (Figure S9, Supporting Information). After subjecting this sequence to the standard hot piperidine treatment $\left(90^{\circ} \mathrm{C}, 30 \mathrm{~min}\right)$, the gel electrophoresis analysis showed that the original M+16 adduct transforms to other products that have a slightly greater mobility than the parent oligonucleotide $(M+16)$ irradiation product (see, Figure $S 9$ in Supporting Information). However, no strand breaks at the sites $G_{1}$ and $G_{2}$ (identified by comparison with standard Maxam-Gilbert G-sequencing lanes) were detected. In contrast, 5'-

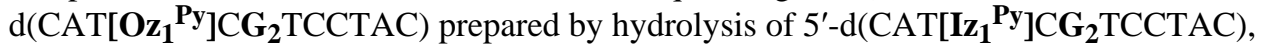
exhibit well-defined hot piperidine-mediated strand breaks at position $\mathrm{G}_{1}$. These observations, in combination with the exonuclease digestion ladder of the parent $5^{\prime}-\mathrm{d}\left(\mathrm{CAT}\left[\mathbf{I z}_{\mathbf{1}}{ }^{\mathbf{P y}}\right]\right.$

$\mathbf{C G}_{2}$ TCCTAC) adduct (see, Figure S6 in Supporting Information) provide strong evidence that the guanine $\mathrm{G}_{1} \mathrm{Py}$ is transformed to the $\mathrm{Iz}^{\mathrm{Py}} / \mathrm{Oz}{ }^{\mathrm{Py}}$ lesions.

The nature of the M+16 adduct eluting at 22 min (fraction 1 in Figure 3) was further investigated. This M+16 oligonucleotide sequence was completely digested by nuclease P1 and alkaline phosphatase to the level of 2'-deoxyribonucleosides (see below). A typical reversed-phase HPLC elution profile of the enzymatic digest (Figure S10, Supporting Information) shows that the M+16 nucleoside elutes after the normal, unmodified nucleosides (dCyd, dGuo, dThd and dAdo), but before the authentic standard (+)-trans-anti-[Py]- $N^{2}-8$ oxodGuo that was added to the sample after completion of the enzymatic digestion. In contrast to the $[\mathrm{Py}]-N^{2}-8$-oxodGuo, the $\mathrm{M}+16$ nucleoside is insensitive to amperometic detection (inset in Figure S10). Moreover, we found that the [Py]- $N^{2}-8$-oxodGuo adduct standard is not detectable by the amperometric method if it is added to the incubation mixture before the enzymatic digestion. This indicates that $[\mathrm{Py}]-N^{2}-8$-oxodGuo decomposes during the enzymatic digestion of the M+16 oligonucleotide sequence. These observations clearly indicate the $M$ +16 nucleoside does not contain the 8-oxodGuo moiety that could have accounted for the additional mass of 16 units of this oxidation product.

In contrast to the unstable 8-oxoGuo lesions generated by oxidation of $\mathrm{G}_{1}{ }^{\mathrm{Py}}$, the 8-oxoGuo lesions derived from oxidation of either the $\mathrm{G}_{2}$ sites in the modified strand, or any of the 
guanines in the complementary strand, $5^{\prime}-\mathrm{TG}_{3} \mathrm{TAG}_{4} \mathrm{G}_{5} \mathrm{ACG}_{6} \mathrm{CATG}_{7} \mathrm{~T}$, are expected to be observable. To estimate the levels of the latter lesions, the irradiated duplexes were completely digested by nuclease P1 and alkaline phosphatase to the level of 2'-deoxyribonucleosides. Using the amperometric method, we found that the yields of 8-oxoGuo generated by a $5-30$ $\mathrm{s}$ irradiation of the DNA duplexes are small ( $1.5 \%$ per duplex, or $\sim 0.2 \%$ per guanine residue), and that 8-oxo-Guo is not a major reaction products under our conditions.

The mass of the M+16 nucleoside was confirmed by the ESI-MS/MS method. We found that the mass spectra recorded in the positive mode exhibit a molecular ion signal at $\mathrm{m} / \mathrm{z} 586.2(\mathrm{M}$ +16 ). The fragmentation pattern of this ion yielded a signal at $\mathrm{m} / \mathrm{z} 470.1$, corresponding to the detachment of the sugar residue to yield the M-116 ion (see, Figure S11 in Supporting Information). The loss of the intact sugar residue of the correct mass, indicates that the additional mass of 16 units in the $\mathrm{M}+16$ lesion is associated with the $\mathrm{G}_{1}{ }^{\mathrm{Py}}$ nucleobase adduct.

Increasing the laser energy dosage, or laser pulse energy (corresponding to a $70-80 \%$ damage of the starting sequence) (Figure 4) generates, besides the $\mathrm{Iz}^{\mathrm{Py}}$ and $\mathrm{M}+16$ lesions already discussed, a broader spectrum of Py-containing products that are only partially resolved by reversed-phase HPLC (see, Figure S3 in Supporting Information). Under these relatively high levels of irradiation, we identified in addition to the $\mathrm{Iz}^{\mathrm{Py}}$ and $\mathrm{M}+16$ adducts, the 5'-d $\left(\mathrm{CATG}_{\mathbf{1}} \mathbf{C G}_{\mathbf{2}}\right.$ TCCTAC) oligonucleotide $(\mathrm{m} / \mathrm{z} 3580.4, \mathrm{M}-302$, arising from the loss of a Py residue), and the abasic sequence, $5^{\prime}-\mathrm{d}\left(\mathrm{CAT}_{-} \mathrm{CG}_{\mathbf{2}} \mathrm{TCCTAC}\right)(\mathrm{m} / \mathrm{z} 3447.7, \mathrm{M}-435)$ that elutes earlier (15 - $20 \mathrm{~min}$ ) than the Py-containing products (for more details, see Figure S3 in Supporting Information). The sequences with abasic sites observed in the HPLC elution profiles contain intact 2-deoxyribose residues. Indeed, the mass of these sequences (M-435) is consistent with the loss of $\mathrm{G}^{\mathrm{Py}}$ that arises from the simple depurination of the modified guanine residue with a weakened $\mathrm{N}$-glycosidic bond. The formation of the abasic site with a lactone moiety ${ }^{34}$ can be ruled out because this species would have a mass smaller by 2 amu than we observed.

\section{Mechanistic Aspects of Iz Lesion Formation: Effect of Cu,Zn-SOD}

Our previous experiments have shown that the Iz lesions arise via the combination reaction of $\mathrm{G}(-\mathrm{H})^{\bullet}$ with $\mathrm{O}_{2}{ }^{--}$radicals that can be monitored by the decay of the $\mathrm{G}(-\mathrm{H})^{\bullet}$ absorbance at 315 $\mathrm{nm} .{ }^{30}$ The time dependence of the $315 \mathrm{~nm}$ absorbance $\left(A_{t}\right)$ at time $t$, can be described by the following expression, obtained by integrating the differential equation for second order kinetics: ${ }^{30}$

$$
A_{t}=\left(A_{0}-A_{\infty}\right) /\left[1+A_{0}\left(k_{4} / \varepsilon_{315}\right) t\right]+A_{\infty}
$$

where, $A_{0}$ is the absorbance at $t=0$, i.e., at the earliest measurable time point after the actinic laser flash, and $A_{\infty}$ is the final absorbance. The value of $k_{4}$ calculated by fitting the above equation to the transient absorption profiles at $315 \mathrm{~nm}$ is $\sim 1.9 \times 10^{8} \mathrm{M}^{-1} \mathrm{~s}^{-1}$ that is close to the value of $4.7 \times 10^{8} \mathrm{M}^{-1} \mathrm{~s}^{-1}$ reported for a guanine radical in an unmodified oligonucleotide sequence. ${ }^{30}$ The superoxide anion is characterized by an absorption band 35 near $250 \mathrm{~nm}$ that overlaps with the strong absorbance band of the oligonucleotide below $300 \mathrm{~nm}$. Therefore, it is impractical to directly monitor the kinetics of the superoxide anion in this wavelength region. We utilized another approach to verify that the reaction partner of $\mathrm{G}(-\mathrm{H})^{\bullet}$ is indeed the superoxide anion. ${ }^{30}$ The $\mathrm{G}(-\mathrm{H})^{\bullet}$ radical decay kinetics were compared in the absence and in the presence of $\mathrm{Cu}, \mathrm{Zn}$ superoxide dismutase which is known to react rapidly with $\mathrm{O}_{2}{ }^{\cdot-36,37}$ Indeed, addition of $5 \mu \mathrm{M} \mathrm{Cu}, \mathrm{Zn}-\mathrm{SOD}$, significantly increases the lifetime of the $\mathrm{G}(-\mathrm{H})^{\circ}$ radicals because superoxide anions shorten the lifetime of the guanine radicals in the absence of this enzyme (Figure 3C). As expected, addition of $\mathrm{Cu}, \mathrm{Zn}-\mathrm{SOD}$ did not affect the Py ${ }^{\bullet+}$ decay at 455 $\mathrm{nm}$ (data not shown). In agreement with this interpretation, the addition of Cu,Zn-SOD (5 $\mu \mathrm{M})$ completely suppresses the formation of the Iz adducts (Figure 3B). 


\section{Time Course of Damage Monitored by Gel Electrophoresis}

We verified that oxidative events are intramolecular rather than bimolecular (see, Supporting Information). Typical results for the single- and double-stranded forms are depicted in the gel autoradiographs in Figures 5 and 6, respectively. Oligonucleotide strand cleavage is negligible in the unirradiated control samples, but a small extent of cleavage above background is observed with unirradiated, but hot piperidine-treated samples (lanes 1 and 2, respectively). However, upon irradiation followed by hot piperidine treatment, cleavage is clearly detectable and the extent of damage increases as a function of irradiation time. The decay profile of the undamaged d(CAT[ $\left.\mathbf{G}_{\mathbf{1}}{ }^{\mathbf{P y}}\right] \mathbf{C G}_{\mathbf{2}}$ TCCTAC) sequence, calculated by integration of the histograms of the original autoradiogram (Figure 5), is very close to that calculated from the HPLC elution profiles (Figure 4).

\section{Hot Piperidine-mediated Cleavage in Single-stranded Sequences}

The sites of the alkali-labile strand cleavage revealed by hot piperidine treatment were identified by the $\mathrm{G}$ and T Maxam-Gilbert sequencing reactions (Figures S12 and S13, Supporting Information). In the case of the $5^{\prime}-\mathrm{d}\left(\mathrm{CAT}\left[\mathbf{G}_{\mathbf{1}}{ }^{\mathbf{P y}}\right] \mathbf{C G}_{\mathbf{2}}\right.$ TCCTAC) sequence in the single-stranded form, the strand cleavage induced by the hot piperidine treatment occurs mostly at the $\mathrm{G}_{1}$ site, while cleavage at the $\mathrm{G}_{2}$ site is less efficient. In contrast, the alkali-labile strand breaks at both $G_{1}$ and $G_{2}$ sites are clearly observed in the experiments when the same oligonucleotides were labeled at the $3^{\prime}$-termini (Figures 5B and S12B). These sequences contain one additional nucleotide introduced by the $3^{\prime}$-endlabeling method, and the oligonucleotides therefore exhibit lower electrophoretic mobilities than the $5^{\prime}$-endlabeled oligonucleotides (Figures 5A and 5B).

\section{Hot Piperidine-mediated Cleavage in the Double-stranded Form}

In the case of the $5^{\prime}$-d(CAT[ $\left.\mathbf{G}_{\mathbf{1}}{ }_{\mathbf{P y}}\right] \mathrm{CG}_{\mathbf{2}}$ TCCTAC) sequence in the double-stranded form (Figure 6) the hot alkali - induced cleavage is less selective than in the experiments with the single-stranded sequence (Figure 5). Identification of the cleavage sites by the $\mathrm{G}$ and T MaxamGilbert sequencing reactions (Figure S13, Supporting Information) shows that, in addition to the strand breaks at the $\mathbf{G}_{\mathbf{1}} \mathbf{P y}$ and $\mathrm{G}_{2}$ sites, cleavage also occurs at the $\mathrm{C}$ between $\mathrm{G}_{1} \mathrm{Py}$ and $\mathrm{G}_{2}$, and at the $\mathrm{T}$ adjacent to $\mathrm{G}_{1}{ }^{\mathrm{Py}}$. A greater extent of cleavage is observable at $\mathrm{G}_{2}$ in the $3^{\prime}$ endlabeling experiments (Figure 6B) than in the $5^{\prime}$-endlabeling experiments (Figure 6A). In the 5 '-endlabeling experiments, the extent of cleavage at $\mathrm{G}_{2}$ in the unirradiated control sample (lane 2) and in the irradiated samples (lanes $3-10$ ) is similar.

\section{Comparisons of Oxidatively Generated Damage at $\mathrm{G}_{\mathbf{1}} \mathrm{Py}$ and at $\mathrm{G}_{\mathbf{2}}$}

We focus on the short irradiation time interval (the first 5 seconds) since DNA damage does not exceed $10 \%$ (single-hit conditions) and the cleavage increases linearly with increasing irradiation time (Figures 7 and 8). The complete time course over the entire time intervals studied ( 0 to $60 \mathrm{~s}$ irradiation time) is shown in Figures S14 and S15. The relative initial rates of reaction at $\mathrm{G}_{1}{ }^{\mathrm{Py}}$ and $\mathrm{G}_{2}$ can be estimated from the linear plots in Figures 7 and 8 . In the 5'endlabeled single-stranded sequences (Figure $7 \mathrm{~A}$ ), the ratios of initial cleavage rates, $\left[\mathrm{G}_{1}{ }^{\mathrm{Py}}\right] /$ $\mathrm{G}_{2}=5.7 \pm 1.2$, is greater than the ratio of $3.0 \pm 0.6$ observed in the 3 '-endlabeling experiments (Figure 7B). In the double-stranded case, cleavage is observed only at $\mathrm{G}_{1}{ }^{\mathrm{Py}}$ in $5^{\prime}$-endlabeled sequences, while the $\left[\mathrm{G}_{1}{ }^{\mathrm{Py}}\right] / \mathrm{G}_{2}$ cleavage ratio is $2.6 \pm 0.4$ (Figure $8 \mathrm{~B}$ ) in the $3^{\prime}$-endlabeling case.

These differences may be understood in terms of damage at both $\mathrm{G}_{1}{ }^{\mathrm{Py}}$ and $\mathrm{G}_{2}$ in the same strand (tandem lesions), or only at $\mathrm{G}_{1}{ }^{\mathrm{Py}}$, or only at $\mathrm{G}_{2}$, assuming that both sites are hot alkalilabile and are cleaved with equal probabilities. In the case of tandem lesions in the 3'endlabeling experiments, only cleavage at $\mathrm{G}_{2}$ should be observed (at the guanine site closest to the radioactively labeled terminus). In contrast, in the 5 '-endlabeling experiment, only 
cleavage at $\mathrm{G}_{1}{ }^{\mathrm{Py}}$ would be observable in the case of strands with tandem lesions. If only $\mathrm{G}_{2}$ is damaged, then both the $5^{\prime}$ - and $3^{\prime}$-endlabeling experiments will exhibit cleavage only at $\mathrm{G}_{2}$. Similarly, damage solely at $\mathrm{G}_{1}{ }^{\mathrm{Py}}$ should be revealed as cleavage at $\mathrm{G}_{1}{ }^{\mathrm{Py}}$ in both cases.

In the single-stranded case, we observe damage at $\mathrm{G}_{1} \mathrm{Py}$ and $\mathrm{G}_{2}$ in both types of labeling experiments, indicating that sequences exist that have damage only at $\mathrm{G}_{1}{ }^{\text {Py }}$ or only at $\mathrm{G}_{2}$. Since the ratio of $\left[\mathrm{G}_{1}{ }^{\mathrm{Py}}\right] / \mathrm{G}_{2}$ slopes are greater in the $5^{\prime}$-endlabeling than the $3^{\prime}$-endlabeling experiments, we conclude that damage at $\mathrm{G}_{1} \mathrm{Py}$ is more probable than at $\mathrm{G}_{2}$. Since damage exists separately at $\mathrm{G}_{2}$ without $\mathrm{G}_{1}{ }^{\mathrm{Py}}$ also being damaged, oxidation of $\mathrm{G}_{2}$ by the Py ${ }^{*+}$ radical competes with oxidation of $\mathrm{G}_{1}$ in the single-stranded molecules (Figure 5).

In the case of the double-stranded sequence, damage at $\mathrm{G}_{2}$ is not observed at all if the strands are $5^{\prime}$-endlabeled (Figure 8A), while it is observable in the $3^{\prime}$-endlabeling experiments, and the $\left[\mathrm{G}_{1}{ }^{\mathrm{Py}}\right] / \mathrm{G}_{2}$ slope is $\sim 2.6$ (Figure $8 \mathrm{~B}$ ). Taken together, these results indicate that tandem lesions at both $\mathrm{G}_{1}$ Py and $\mathrm{G}_{2}$ can occur on the same strand, or damage can exist only at $\mathrm{G}_{1}{ }^{\mathrm{Py}}$ with $\mathrm{G}_{2}$ remaining undamaged on the same strand. There are no strands in which only $\mathrm{G}_{2}$ is damaged in the double-stranded form.

At the longer irradiation times (particularly pronounced in lanes 7-10 in panel A, and 8-10 in panel B in Figures 5 and 6, respectively) new bands appear (labeled UM) that co-migrate with the unmodified 11-mers 5'-d(CATG $\mathbf{C G}_{\mathbf{1}} \mathbf{G}_{\mathbf{2}}$ TCTAC) sequence. This sequence arises from a loss of the Py residue that becomes visible after prolonged irradiation. The loss of the undamaged $5^{\prime}$-d $\left(\mathrm{CATG}_{\mathbf{1}} \mathrm{CG}_{\mathbf{2}}\right.$ TCCTAC) sequence under these irradiation conditions was confirmed in separate experiments using reversed-phase HPLC and MALDI-TOF/MS analysis (data not shown), and G and T Maxam-Gilbert sequencing reactions (Figures S12 and S13, Supporting Information). The slowly migrating UM band co-migrates with the band of the authentic 5'-d(CATG $\mathbf{C G}_{\mathbf{2}}$ TCCTAC) sequence labeled either from the 5'- or the 3'-end as shown in Supporting Information (Figures S12 and S13). We were unable to identify any tandem lesions under these extended irradiation conditions by HPLC since only a broad spectrum of overlapping, partially resolved products is observed (Figure S3B). In contrast to the hot alkali - gel electrophoresis assays, sequences in which both $\mathrm{G}_{1}$ and $\mathrm{G}_{2}$, or $\mathrm{G}_{1} \mathrm{Py}$ and $\mathrm{G}_{2}$ are damaged were not detectable by MALDI-TOF/MS analysis (data not shown) for reasons that remain to be elucidated.

\section{Guanine Photodamage in the Unmodified Complementary Strand}

Damage on the unmodified complementary strand in duplexes of $5^{\prime}$-d(CAT[ $\left.\mathbf{G}_{\mathbf{1}}{ }^{\mathbf{P y}}\right]$

$\mathrm{CG}_{2}$ TCCTAC) with the strand $5^{\prime}-\mathrm{TG}_{3} \mathrm{TAG}_{4} \mathrm{G}_{5} \mathrm{ACG}_{6} \mathrm{CATG}_{7} \mathrm{~T}$ (Figure 1 ) containing one extra $T$ base at each end (for better visualization of cleavage at $G_{3}$ and $G_{7}$ in the high resolution denaturing polyacrylamide gels), was explored. After photoexcitation of these DNA duplexes, oxidative modifications in the unmodified complementary strands was revealed by the standard hot piperidine treatment (Figure 9).

Cleavage at guanine sites is more pronounced after the hot piperidine treatment. The relative cleavage efficiencies at guanine sites are different. Cleavage at $\mathrm{G}_{3}$ and $\mathrm{G}_{7}$, i.e., at sites that are closest to the ends of the oligonucleotide, are significantly greater than at the inner $\mathrm{G}_{4}, \mathrm{G}_{5}$, and $\mathrm{G}_{6}$ sites that are positioned closer to the center of the duplex. The extent of DNA damage at the complementary strand strongly increases with laser power (Figure 10) as in the case of the Py-modified strand (Figure 4).

However, at the same laser energy and irradiation time, cleavage at the Py-modified strand is significantly more efficient than in the complementary strand by a factor of $\sim 10$ (compare Figures 4 and 10). A MALDI-TOF/MS analysis of the complementary strands obtained from irradiated duplexes clearly exhibit signals at $m / z, 3669.5$ that correspond to a mass of $\mathrm{M}_{\mathrm{C}^{-}} 39$ 
since the mass of the intact complementary strand is $\mathrm{M}_{\mathrm{C}}=3709.5$ (data not shown). This mass corresponds to the formation of single Iz lesions in the complementary strand. These observations, as well as the fact that oxidative cleavage occurs at all guanines (Figure 9), suggest that the lesion Iz can form at all guanine sites in the complementary strand.

\section{Discussion}

\section{Selective Oxidation of Guanine in DNA by Photoexcitation of Covalently Linked Pyrenyl Radical Cations}

The direct spectroscopic time-resolved measurements described here demonstrate that photoexcitation of Py- $N^{2}$-dG adducts, site-specifically incorporated into an oligonucleotide and irradiated with intense $355 \mathrm{~nm}$ laser pulses, induces the selective ionization of the Py residues followed by the formation of $\mathrm{Py}^{\bullet+}$ radical cations and hydrated electrons (Figure 2) according to the scheme:

$$
\left[\mathrm{G}_{1}-\mathrm{Py}\right]-\text { oligo }-\mathrm{G}_{2}+h v \rightarrow\left[\mathrm{G}_{1}-{ }^{1} \mathrm{Py}\right]-\text { oligo }-\mathrm{G}_{2}+h v \rightarrow\left[\mathrm{G}_{1}-\mathrm{Py}{ }^{\bullet+}\right]-\text { oligo }-\mathrm{G}_{2}+e_{\mathrm{aq}}{ }^{-}
$$

where $\left[\mathrm{G}_{1}-\mathrm{Py}\right]$-oligo-G ${ }_{2}=5^{\prime}$-d $\left(\mathrm{CAT}\left[\mathbf{G}_{\mathbf{1}} \mathbf{P y}^{\mathbf{P y}}\right] \mathbf{C G}_{\mathbf{2}}\right.$ TCCTAC). The two-photon ionization mechanism is a convenient mechanism for oxidizing the covalently modified guanine residue $\mathrm{G}_{1}$ and thus injecting a hole into the oligonucleotide that allows for the spectroscopic, simultaneous monitoring of the primary electron donor and acceptor species. Possible generation of singlet oxygen derived from the quenching of the Py excited states by ${ }^{3} \mathrm{O}_{2}$ was ruled out because the results of the classical tests ${ }^{38-43}$ on singlet oxygen were negative. ${ }^{44}$ Addition of the typical scavengers ${ }^{38-43}$ of singlet oxygen $(10 \mathrm{mM}$ sodium azide or $10 \mathrm{mM}$ 2-mercaptoethanol) did not affect the distributions of the cleavage patterns and their yields. Enhancement of DNA damage in $\mathrm{D}_{2} \mathrm{O}$ buffer solutions, expected if DNA damage is induced by a singlet oxygen mechanism ${ }^{38-40}$ was not detected. Moreover, distributions and yields of the cleavage patterns were identical in $\mathrm{H}_{2} \mathrm{O}$ and $\mathrm{D}_{2} \mathrm{O}$ buffer solutions. The results of these experiments rule out the formation of oxidatively generated damage to DNA by singlet oxygen 44 in agreement with the results of Sigman et al. who did not find any products associated with reactions of singlet oxygen in the course of pyrene photolysis in aqueous and surfactant solutions. ${ }^{45}$

The $\mathrm{Py}^{\circ+}$ radical cations rapidly oxidize the covalently linked $\mathrm{G}$ residues in the $\left[\mathrm{G}_{1}-\mathrm{Py}^{\circ+}\right]$ state generated under our intense laser pulse irradiation conditions. ${ }^{21}$ The decay of the $\mathrm{Py}^{\circ+}$ cation radicals occurs within two distinct time domains: (i) a prompt decay channel $(<100 \mathrm{~ns})$ that is not resolved in our experiments, and (ii) a slower decay phase that is well-resolved on the $\mu s$-time scale (Figure 2B). The appearance of the guanine radical absorbance at $315 \mathrm{~nm}$, also shows a rapid rise followed by a slower rise (Figure 2B) that is correlated with the slower decay phase of the $\mathrm{Py}^{*+}$ radical cation. This electron transfer process is equivalent to the transfer of a hole from the $\mathrm{Py}^{\bullet+}$ residue to the guanine base to which it is attached covalently:

$\left[\mathrm{G}_{1}-\mathrm{Py}^{\bullet+}\right]-$ oligo $-\mathrm{G}_{2} \rightarrow\left[\mathrm{G}_{1}^{\bullet+}-\mathrm{Py}\right]-$ oligo $-\mathrm{G}_{2} \rightarrow\left[\mathrm{G}(-\mathrm{H})_{1}^{\bullet}-\mathrm{Py}\right]-$ oligo $-\mathrm{G}_{2}+\mathrm{H}^{+}$

The observed biphasic kinetics (Figure 2B) have been observed in previous experiments of electron transfer reactions in DNA and are attributed to fluctuations in electron donor-acceptor conformations. 46

The guanine radicals identified by their absorbance at $315 \mathrm{~nm}$ (Figure 2A) cannot be unambiguously assigned to the $\mathrm{G}^{\bullet+}$ or $\mathrm{G}(-\mathrm{H})^{\bullet}$ radical forms because the transient absorption spectra of these two species are very close to one another. ${ }^{11,24,46}$ Nevertheless, recent pulse radiolysis experiments showed that even in double-stranded DNA, the deprotonation of the $\mathrm{G}^{\bullet+}$ radical cation is very fast $\left(\sim 300 \mathrm{~ns},{ }^{28}\right)$ and that the radicals detected in our transient absorption experiments can thus be assigned to the neutral form. 


\section{Fates of G(-H) $)^{\bullet}$ Radicals in DNA in Aqueous Solutions: Two- and Four-Electron Oxidation Products}

Utilizing time-resolved spectroscopic methods, we have demonstrated that hole injection can occur at the $\mathrm{G}_{1}$ site in the oligonucleotide 5'-d(CAT[ $\left.\mathbf{G}_{\mathbf{1}} \mathbf{P y}_{\mathbf{y}}\right] \mathbf{C G}_{\mathbf{2}}$ TCCTAC) to form $\mathrm{G}^{\bullet+} / \mathrm{G}(-$ $\mathrm{H})^{\bullet}$ radicals, the products of a one-electron oxidation of guanine. The $\mathrm{G}^{\bullet+} / \mathrm{G}(-\mathrm{H})^{\bullet}$ radicals embedded in this DNA strand do not react to any observable extent with molecular oxygen (rate constant $<10^{3} \mathrm{M}^{-1} \mathrm{~s}^{-1}$ ). $16,30,47,48$ The transformation of the $\mathrm{G}^{\bullet+} / \mathrm{G}(-\mathrm{H})^{\bullet}$ radicals resulting in the formation of stable oxidized product molecules always results from the overall abstraction of even numbers $(2,4$ etc.) of electrons that can involve two potential pathways:

(i) addition of nucleophiles (e.g., $\mathrm{H}_{2} \mathrm{O}$ ), followed by the abstraction of a second electron, and (ii) combination of the $\mathrm{G}^{*+} / \mathrm{G}(-\mathrm{H})^{\bullet}$ radicals with other free radicals that in turn can be oneelectron (e.g., ${ }^{\circ} \mathrm{NO}_{2}$ ), or three-electron oxidants such as the superoxide anion radical derived from the trapping of the hydrated electrons. Indeed, in agreement with our previous observations, ${ }^{30}$ addition of $\mathrm{Cu}, \mathrm{Zn}-\mathrm{SOD}$, which is known to react rapidly with $\mathrm{O}_{2}{ }^{-}, 49,50$ results in a remarkable increase in the lifetime of the $\mathrm{G}(-\mathrm{H})^{\bullet}$ radicals (Figure $3 \mathrm{C}$ ). This enhancement is consistent with the combination of the $\mathrm{G}(-\mathrm{H})^{\bullet}$ and $\mathrm{O}_{2}{ }^{-}$radicals that is significantly reduced in the presence of $\mathrm{Cu}, \mathrm{Zn}-\mathrm{SOD}$, a scavenger of the superoxide anion radical.

The addition of the three-electron oxidant, $\mathrm{O}_{2}{ }^{--}$to the one-electron oxidation product, $\mathrm{G}(-$ $\mathrm{H})^{\bullet}$, results in the formation of the $\mathrm{Iz}^{\mathrm{Py} / \mathrm{Oz}}{ }^{\mathrm{Py}}$ lesions that are products of four-electron oxidation of the modified guanine $\left(\mathrm{G}_{1}{ }^{\mathrm{Py}}\right)$ in the oligonucleotide $5^{\prime}$-d(CAT[ $\left.\mathbf{G}_{\mathbf{1}}{ }^{\mathbf{P y}}\right] \mathbf{C G}_{\mathbf{2}}$ TCCTAC). There are two bimolecular radical-radical reactions that compete with one another: ${ }^{30}(i)$ oxidation of $\mathrm{O}_{2}{ }^{\cdot-}$ by the $\mathrm{G}(-\mathrm{H})^{\bullet}$ radical (reaction 3 ) that results in the recovery of $\mathrm{O}_{2}$ and undamaged $\mathrm{G}$ (reaction 3), and (ii) the addition of $\mathrm{O}_{2}{ }^{--}$to the $\mathrm{C} 5$ position of $\mathrm{G}(-\mathrm{H})^{\bullet}$ (reaction 4) that, upon protonation, results in the formation of a 5-HOO-G(-H) intermediate product that decomposes to the Iz, and finally to $\mathrm{Oz}$ lesions according to the mechanism originally proposed by Cadet and co-workers: ${ }^{31}$

$\left[\mathrm{G}(-\mathrm{H})_{1}^{\bullet}-\mathrm{Py}\right]-$ oligo $-\mathrm{G}_{2}+\mathrm{O}_{2}^{\bullet-} \rightarrow\left[\mathrm{G}_{1}-\mathrm{Py}\right]-$ oligo $-\mathrm{G}_{2}+\mathrm{O}_{2}$

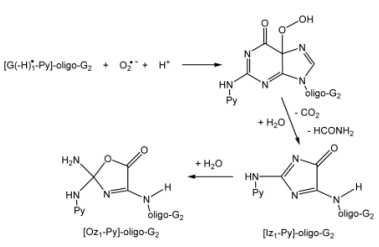

In the case of unmodified G(-H) ${ }^{\bullet}$ radicals embedded in the DNA sequences, the two-electron oxidation pathway leading to 8-oxodGuo lesions is much less efficient than the combination reactions ( 3 and 4 ). It has indeed been shown that 8 -oxodGuo, obtained by enzymatic digestion of single- and double-stranded oligonucleotides oxidized by the photosensitization of riboflavin (a type I photosensitizer and a one-electron oxidant), was formed in minor quantities in comparison with the Iz/Oz lesions. ${ }^{32,51-53}$ Our own experiments in which oxidation of guanine is mediated by the two-photon ionization of 2-aminopurine residues embedded in single- and double-stranded oligonucleotides, have also shown that the yields of 8-oxodGuo lesions are lower by a factor of $\sim 20$ than the yields of the Iz/Oz lesions. ${ }^{30}$

The formation of the Iz/Oz lesions competes with the formation of the $\mathrm{M}+16$ nucleoside adducts. The latter does not exhibit the same typical amperometric response as the standard [Py]- $N^{2}-8$-oxodGuo adduct (Figure S10) and, therefore, it cannot be identical in structure to 
the [Py]- $N^{2}-8$-oxodGuo adduct even though it has the identical mass. The ESI-MS/MS analysis of M+16 lesions showed that the additional mass of 16 amu resides on the guanine moiety or the Py residue, not on the furanose ring. Here, we propose that the M+16 lesion contains hydroxylated Py residues. Indeed, hydroxylated pyrene derivatives are common products of pyrene photolysis in oxygenated aqueous solutions. ${ }^{45}$ In support of this conclusion, we also found that $\mathrm{M}+16$ is a major products of the photolysis of the Py residue in the $5^{\prime}-\mathrm{CTCT}\left[\mathbf{A}^{\mathbf{P y}}\right.$ ] TTTCC oligonucleotide sequence without guanines containing a single modified adenine residue $\left(\mathrm{A}^{\mathrm{Py}}\right.$ ) that is analogous to the guanine adduct, $\mathrm{G}^{\mathrm{Py}}$, shown in Figure 1 (these studies are currently in progress in our laboratory). The addition of $\mathrm{H}_{2} \mathrm{O}$ (or $\mathrm{OH}^{*}$ ) to the $\mathrm{Py}^{\circ+}$ radical cation can be an important mode of decay of $\mathrm{Py}^{\circ+}$ in the $\mathrm{A}^{\mathrm{Py}}$-containing oligonucleotide 5'${ }_{21}^{\mathrm{CTCT}}\left[\mathbf{A}^{\mathbf{P y}}\right]$ TTTCC since $\mathrm{Py}^{\bullet+}$ radicals are unable to oxidize adenine to any observable extent.

\section{Hole Injection and Propagation of the Damage along the DNA Helix}

The gel-electrophoresis experiments (Figures 6 and 8) demonstrate that oxidative damage at $\mathrm{G}_{1}{ }^{\mathrm{Py}}$ is greater than at $\mathrm{G}_{2}$. This indicates that in double-stranded DNA the oxidation of the $\mathrm{G}_{1}$ residue by the covalently attached $\mathrm{Py}^{\circ+}$ radical cation is faster than the oxidation of $\mathrm{G}_{2}$ by $\mathrm{Py}^{\circ+}$. In turn, hole hopping from $\mathrm{G}_{1}{ }^{\cdot+}$-Py to $\mathrm{G}_{2}$ is slower than the transformation of $\mathrm{G}_{1}{ }^{\cdot+}$-Py to the oxidative end products. An upper limit of hole hopping rates $\left(k_{\mathrm{hh}}\right)$ can be estimated from the known rates of the combination of the $\mathrm{G}(-\mathrm{H})^{\bullet}$ and $\mathrm{O}_{2}{ }^{--}$radicals (reactions 3 and 4). Under our experimental conditions, the characteristic time of the combination reaction is about $2 \mathrm{~ms}$ that give an upper limit of $k_{\mathrm{hh}}<5 \times 10^{3} \mathrm{~s}^{-1}$ for hole hopping from $\mathrm{G}_{1}{ }^{-}-\mathrm{Py}$ to $\mathrm{G}_{2}$. This specific relationship between the rates of hole hopping and the rates of chemical reactions leading to the end products can be associated with the stabilization of $\mathrm{G}_{1}{ }^{\cdot+}$ by electronic interactions with the aromatic ring system of the Py residue linked to $\mathrm{G}_{1}$ that is favored by the very short distance between these two moieties (Figure 1). Electronic interactions between the Py residues and G bases are clearly apparent by the red shift of the maxima of the absorption and fluorescence emission spectra of the covalently-linked adducts. ${ }^{54,55}$ In contrast, preferential damage at guanines covalently linked to other sensitizers such as intercalating rhodium complexes or anthraquinone photosensitizers tethered to DNA by the flexible polymethylene linkers, has not been observed. ${ }^{1-4}$ In the latter systems, multiple configurations of the photosensitizers linked to the covalently modified guanine residues via linker chains of different lengths allow for multiple configurations. The resulting greater average distances between the modified guanine and photosensitizer moieties are likely to diminish any potential stabilization of the holes on the modified guanine residues via analogous short-distance electronic interactions.

Oxidative damage at the guanines in the complementary strand is also less efficient than damage at $\mathrm{G}_{1}$ (Figures 9 and 10). The complementary strand contains five guanines, and holes can migrate freely ${ }^{1-9}$ along this strand in the absence of a stabilization or trapping at any particular site. Oxidative damage is clearly more efficient at the $\mathrm{G}_{3}$ and $\mathrm{G}_{7}$ sites at the termini where fraying of double-stranded oligonucleotides has been thoroughly characterized by NMR methods. ${ }^{56}$ The greater solvent exposure of $\mathrm{G}^{*} / \mathrm{G}(-\mathrm{H})^{\bullet}$ radicals may give rise to "hole sinks" at the terminal $\mathrm{G}_{3}$ and $\mathrm{G}_{7}$ positions. In turn, these sites can be also more reactive in bimolecular reactions with radicals (e.g., $\mathrm{O}_{2}{ }^{--}$), or nucleophiles (e.g., solvent molecules), reactions that are necessary for the formation of the end-products (Iz, 8-oxodGuo, etc.). Enhanced damage at the solvent exposed guanines has been observed earlier in the oxidation of DNA and RNA hairpins by $\mathrm{KHSO}_{5}$ catalyzed by $\mathrm{Co}(\mathrm{II})$ and $\mathrm{Ni}(\mathrm{II})$ complexes. ${ }^{57}$

\section{Tandem Model of DNA Damage}

The original autoradiographs of the denaturating gels (Figure 6) show that in double-stranded DNA, oxidative damage at $\mathrm{G}_{2}$ is preceded by damage at the guanine residue of $\mathrm{G}_{1} \mathrm{Py}$ (tandem damage model). In addition, the $\mathrm{C}$ between $\mathrm{G}_{1}{ }^{\mathrm{Py}}$ and $\mathrm{G}_{2}$, and one of the flanking $\mathrm{T}$ bases are 
also alkali labile after irradiation and damage is detectable by gel electrophoresis, especially at the higher levels of irradiation dosage. It is interesting to note that tandem lesions characterized by damage at $G_{2}$, in addition to damage at $G_{1}$, can be detected under single-hit conditions at low levels $(<10 \%)$ of overall DNA damage (Figure 8$)$. The appearance of the tandem lesions under these single-hit conditions suggests that one primary photochemical event does not necessarily produce only one damage event. Indeed, in our system, a single photochemical event (the photoionization of pyrene), or a "single hit", produces four oxidizing equivalents: the pyrenyl radical cation (a one-electron oxidant), and the superoxide anion (a three-electron oxidant) derived from the trapping of hydrated electrons by molecular oxygen. Here, we hypothesize that a hydroperoxide adduct $[5-\mathrm{HOOG}(-\mathrm{H})]$ derived from the combination of $\mathrm{G}(-\mathrm{H})^{\bullet}$ and $\mathrm{O}_{2}^{\bullet-}$ radicals (reaction 4 ) can be activated to form secondary oxyl $\left[{ }^{\circ} \mathrm{OG}(-\mathrm{H})\right]$ or peroxyl $\left[{ }^{\circ} \mathrm{OO}-\mathrm{G}(-\mathrm{H})\right]$ radicals. The latter radicals can induce not only damage at $\mathrm{G}_{2}$ to form tandem lesions, but can also abstract $\mathrm{H}$-atoms from nearby $\mathrm{T}$ and $\mathrm{C}$ bases, thus leading to further oxidation events and the formation of alkali-labile lesions at these sites. Similar sequence of events triggered by the thymine peroxyl radicals has been proposed by Cadet et al. for formation of the G-T tandem lesions in DNA exposed to ionizing radiation. 58 This hypothesis can account for the formation of tandem lesions even at low dosages under so-called "single hit" conditions when only a fraction $(<10 \%)$ of oligonucleotide strands are damaged (Figure 8).

Increasing the laser energy dosage (multiple-hit conditions) results in a greater multiplicity of lesions (Figure S3) than under single-hit conditions (Figure 6). This enhancement of the multiplicity of lesions at high levels of irradiation is associated with a consecutive excitation, or multiple-hit conditions. After the guanine radicals at $\mathrm{G}_{1}$ combine with superoxide radicals, the $\mathrm{Iz}_{1}$ Py lesion is formed. The Iz residues are not susceptible to further oxidation, and the Py residues in $\mathrm{Iz}_{1} \mathrm{Py}$ can be photoexcited to generate once more the excited $\mathrm{Py}^{\bullet+}$ radical that can then oxidize $G_{2}$ at a distance thereby giving rise to further oxidation events, including the formation of tandem lesions. Since the Py residue is also gradually oxidized as the dosage is increased, the formation of tandem lesions or multiple lesions will assume a complex, nonlinear dependence on the irradiation dosage. This phenomenon leads to a saturation of oxidative damage at $G_{1} P y$ and $G_{2}$ with increasing irradiation time and under multiple-hit conditions (Figure S14). The saturation of damage in the unmodified complementary strand as a function of irradiation time at two different laser pulse energies is also observable in the case of the complementary strand (Figure 10).

In summary, the generation of tandem lesions is observable under single-hit and multiple-hit conditions and requires the oxidation of $G_{1}$ Py before $G_{2}$ on the same strand can be oxidized.

\title{
Supplementary Material
}

Refer to Web version on PubMed Central for supplementary material.

\begin{abstract}
Acknowledgements
The authors wish to thank Dr. J. Cadet for insightful discussion, and Dr. S. Amin for a gift of anti-BPDE. This work was supported by the National Institutes of Health, Grants 1 R01 CA110261, and CA26735 (for P.C.D.), and by NIH grant CA099194 that supported the synthesis of the Py-modified oligonucleotides, and by a grant from the Kresge Foundation. Young-Ae Lee gratefully acknowledges support from the Post-Doctoral Fellowship Program of the Korean Science and Engineering Foundation. Components of this work were conducted in the Shared Instrumentation Facility at NYU that was constructed with support from Research Facilities Improvement Grant C06 RR-16572 from the National Center for Research Resources, NIH. The acquisition of the LCQ-Ion trap spectrometer was supported by NSF Chemical instrumentation Program Grant CHE-0234863.
\end{abstract}

\section{References}

1. Nunez ME, Hall DB, Barton JK. Chem Biol 1999;6:85-97. [PubMed: 10021416] 
2. Schuster GB. Acc Chem Res 2000;33:253-260. [PubMed: 10775318]

3. Giese B. Annu Rev Biochem 2002;71:51-70. [PubMed: 12045090]

4. Hall DB, Holmlin RE, Barton JK. Nature 1996;382:731-735. [PubMed: 8751447]

5. Lewis FD, Letsinger RL, Wasielewski MR. Acc Chem Res 2001;34:159-170. [PubMed: 11263874]

6. Lewis FD, Liu X, Liu J, Miller S, Hayes RT, Wasielewski MR. Nature 2000;406:51-53. [PubMed: 10894536]

7. Lewis FD, Liu J, Zuo X, Hayes RT, Wasielewski MR. J Am Chem Soc 2003;125:4850-4861. [PubMed: 12696904]

8. Kawai K, Takada T, Tojo S, Ichinose N, Majima T. J Am Chem Soc 2001;123:12688-12689. [PubMed: 11741438]

9. Kawai K, Takada T, Tojo S, Majima T. J Am Chem Soc 2003;125:6842-6843. [PubMed: 12783517]

10. Burrows CJ, Muller JG. Chem Rev 1998;98:1109-1151. [PubMed: 11848927]

11. Steenken S, Jovanovic SV. J Am Chem Soc 1997;119:617-618.

12. Cadet J, Bellon S, Berger M, Bourdat AG, Douki T, Duarte V, Frelon S, Gasparutto D, Muller E, Ravanat JL, Sauvaigo S. Biol Chem 2002;383:933-943. [PubMed: 12222683]

13. Fountain MA, Krugh TR. Biochemistry 1995;34:3152-3161. [PubMed: 7880810]

14. Cosman M, de los Santos C, Fiala R, Hingerty BE, Singh SB, Ibanez V, Margulis LA, Live D, Geacintov NE, Broyde S, Patel DJ. Proc Natl Acad Sci USA 1992;89:1914-1918. [PubMed: 1311854]

15. Mao B, Margulis LA, Li B, Ibanez V, Lee H, Harvey RG, Geacintov NE. Chem Res Toxicol 1992;5:773-778. [PubMed: 1489927]

16. Joffe A, Geacintov NE, Shafirovich V. Chem Res Toxicol 2003;16:1528-1538. [PubMed: 14680366]

17. Shafirovich V, Dourandin A, Huang W, Luneva NP, Geacintov NE. J Phys Chem B 1999;103:1092410933.

18. Shafirovich VY, Levin PP, Kuzmin VA, Thorgeirsson TE, Kliger DS, Geacintov NE. J Am Chem Soc 1994;116:63-72.

19. Floyd RA, Watson JJ, Wong PK, Altmiller DH, Rickard RC. Free Radic Res Commun 1986;1:163172. [PubMed: 2577733]

20. Berger M, Anselmino C, Mouret JF, Cadet J. J Liq Chromatogr 1990;13:929-940.

21. Kuzmin VA, Dourandin A, Shafirovich V, Geacintov NE. Phys Chem Chem Phys 2000;2:15311535.

22. Shafirovich VY, Courtney SH, Ya N, Geacintov NE. J Am Chem Soc 1995;117:4920-4929.

23. Buxton GV, Greenstock CL, Helman WP, Ross AB. J Phys Chem Ref Data 1988;17:513-886.

24. Candeias LP, Steenken S. J Am Chem Soc 1989;111:1094-1099.

25. Stemp EDA, Arkin MR, Barton JK. J Am Chem Soc 1997;119:2921-2925.

26. Stemp EDA, Barton JK. Inorg Chem 2000;39:3868-3874. [PubMed: 11196782]

27. Dohno C, Stemp EDA, Barton JK. J Am Chem Soc 2003;125:9586-9587. [PubMed: 12904014]

28. Kobayashi K, Tagawa S. J Am Chem Soc 2003;125:10213-10218. [PubMed: 12926943]

29. Bielski BHJ, Cabelli DE, Arudi RL, Ross AB. J Phys Chem Ref Data 1985;14:1041-1100.

30. Misiaszek R, Crean C, Joffe A, Geacintov NE, Shafirovich V. J Biol Chem 2004;279:32106-32115. [PubMed: 15152004]

31. Cadet J, Berger M, Buchko GW, Joshi PC, Raoul S, Ravanat JL. J Am Chem Soc 1994;116:74037404.

32. Gasparutto D, Ravanat JL, Gerot O, Cadet J. J Am Chem Soc 1998;120:10283-10286.

33. Mestre B, Nascimben S, Pratviel G, Meunier B. C R Acad Sci Paris 1998;II c:725-736.

34. Chatgilialoglu C, Gimisis T. Chem Commun 1998:1249-1250.

35. Bielski BHJ. Photochem Photobiol 1978;28:645-649.

36. Klug D, Rabani J, Fridovich I. J Biol Chem 1972;247:4839-4842. [PubMed: 4626367]

37. Rotilio G, Bray RC, Fielden EM. Biochim Biophys Acta 1972;268:605-609. [PubMed: 5026315]

38. Lee PC, Rodgers MA. Photochem Photobiol 1987;45:79-86. [PubMed: 3031708]

39. Blazek ER, Peak JG, Peak MJ. Photochem Photobiol 1989;49:607-613. [PubMed: 2755997] 
40. Kochevar, IE.; Dunn, DA. Bioorganic Photochemistry. Morrison, H., editor. Wiley; New York: 1990. p. 273-315.

41. Condorelli G, Constanzo LL, De Guidi G, Giuffrida S, Sortino S. Photochem Photobiol 1995;62:155161. [PubMed: 7638260]

42. Vargas F, Martinez Volkmar I, Sequera J, Mendez H, Rojas J, Fraile G, Velasquez M, Medina R. J Photochem Photobiol B 1998;42:219-225. [PubMed: 9595711]

43. Stevenson C, Davies RJ. Chem Res Toxicol 1999;12:38-45. [PubMed: 9894016]

44. Huang, W. PhD Thesis. New York University; 2001.

45. Sigman ME, Schuler PF, Ghosh MM, Dabestani RT. Environ Sci Technol 1998;32:3980-3985.

46. Shafirovich V, Dourandin A, Huang W, Luneva NP, Geacintov NE. Phys Chem Chem Phys 2000;2:4399-4408.

47. Al-Sheikhly M. Radiat Phys Chem 1994;44:297-301.

48. Shafirovich V, Dourandin A, Huang W, Geacintov NE. J Biol Chem 2001;276:24621-24626. [PubMed: 11320091]

49. Klug D, Rabani J, Fridovich I. J Biol Chem 1972;247:4839-4842. [PubMed: 4626367]

50. Rotilio G, Bray RC, Fielden EM. Biochim Biophys Acta 1972;268:605-609. [PubMed: 5026315]

51. Kino K, Saito I, Sugiyama H. J Am Chem Soc 1998;120:7373-7374.

52. Kino K, Sugiyama H. Chem Biol 2001;8:369-378. [PubMed: 11325592]

53. Kupan A, Sauliere A, Broussy S, Seguy C, Pratviel G, Meunier B. ChemBioChem 2006;7:125-133. [PubMed: 16323222]

54. Gagliano AG, Geacintov NE, Ibanez V, Harvey RG, Lee HM. Carcinogenesis 1982;3:969-976. [PubMed: 7139871]

55. Geacintov NE, Gagliano AG, Ibanez V, Harvey RG. Carcinogenesis 1982;3:247-253. [PubMed: 7083468]

56. Cosman M, de los Santos C, Fiala R, Hingerty BE, Singh SB, Ibanez V, Margulis LA, Live D, Geacintov NE, Broyde S, Patel DJ. Proc Natl Acad Sci USA 1992;89:1914-1918. [PubMed: 1311854]

57. Muller JG, Zheng P, Rokita SR, Burrows CJ. J Am Chem Soc 1996;118:2320-2325.

58. Cadet J, Bellon S, Berger M, Bourdat AG, Douki T, Duarte V, Frelon S, Gasparutto D, Muller E, Ravanat JL, Sauvaigo S. Biol Chem 2002;383:933-943. [PubMed: 12222683] 
<smiles>[R]n1cnc2c(=O)[nH]c(N[C@@H]3c4c(cc5ccc6cccc7ccc4c5c67)[C@@H](O)[C@H](O)[C@@H]3O)nc21</smiles>

\section{$5^{\prime}-\mathrm{CAT}\left[\mathrm{G}_{1}{ }^{\mathrm{Py}}\right] \mathrm{C} \mathrm{G}_{2}$ TC C TAC - ${ }^{\prime}$ 3'- T G $\mathrm{G}_{7} \mathrm{TA} \quad \mathrm{C} \quad \mathrm{G}_{6} \mathrm{C} A \mathrm{G}_{5} \mathrm{G}_{4} \mathrm{AT} \mathrm{G}_{3} \mathrm{~T}-5^{\prime}$}

Figure 1.

Structure of the $10 S(+)$-trans-anti-[Py]- $N^{2}-\mathrm{dG}$ adduct embedded in the oligonucleotide duplex

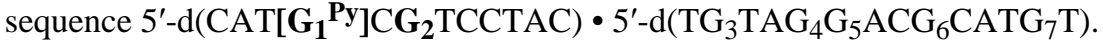



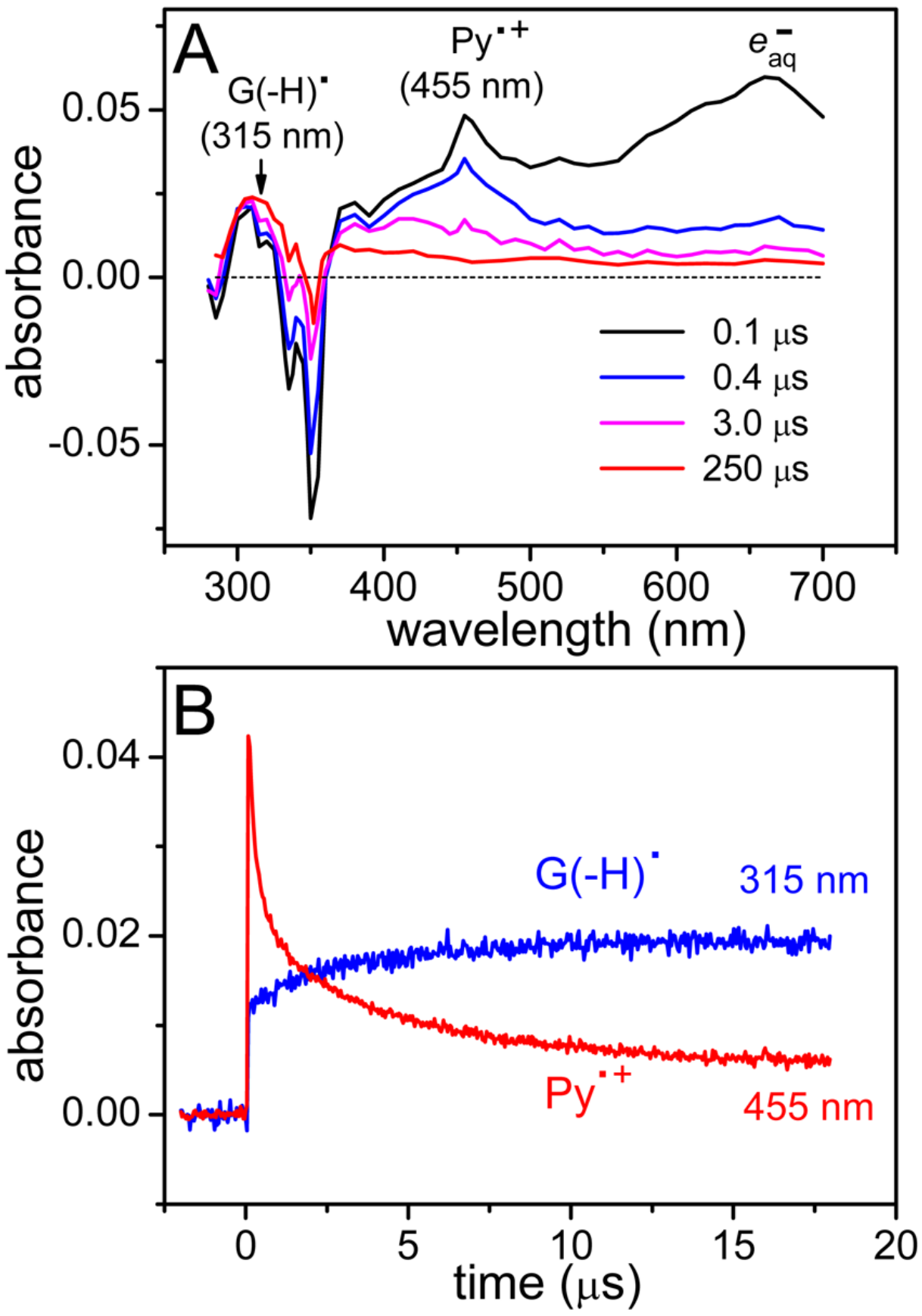

Figure 2.

Transient absorption spectra of the $5^{\prime}$-d $\left(C A T\left[\mathbf{G}_{\mathbf{1}}{ }^{\mathbf{P y}}\right] \mathbf{C G}_{\mathbf{2}}\right.$ TCCTAC) oligonucleotide in the single-stranded form (Panel A) and kinetic traces of the $\mathrm{Py}^{\bullet+}$ and $\mathrm{G}(-\mathrm{H})^{\bullet}$ radicals at $455 \mathrm{~nm}$ and $315 \mathrm{~nm}$, respectively (Panel B). The spectra were recorded at fixed time intervals after a single laser pulse photoexcitation $\left(355 \mathrm{~nm}, 38 \mathrm{~mJ} / \mathrm{cm}^{2}\right.$ ) of the Py photosensitizer residues with the modified oligonucleotide $(100 \mu \mathrm{M})$ dissolved in air-equilibrated $\left(\left[\mathrm{O}_{2}\right] \sim 0.27 \mathrm{mM}\right) 5 \mathrm{mM}$ phosphate buffer solution (pH 7.5) containing $100 \mathrm{mM} \mathrm{NaCl}$. 

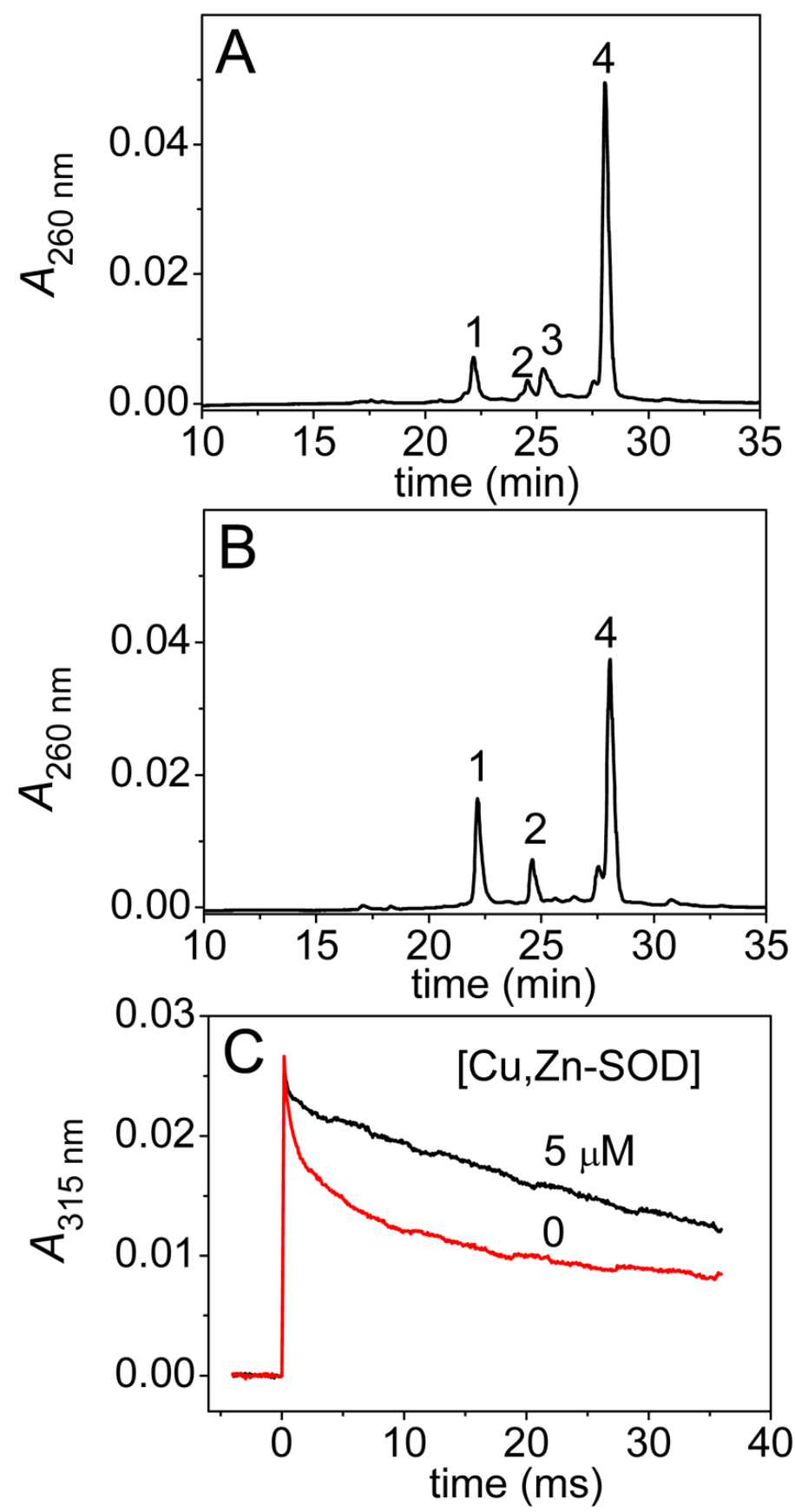

Figure 3.

HPLC elution profiles of photoirradiation products and effect of $\mathrm{Cu}, \mathrm{Zn}$-SOD on end-products of $5^{\prime}-\mathrm{d}\left(\mathrm{CAT}\left[\mathbf{G}_{\mathbf{1}}{ }^{\mathbf{P y}}\right] \mathrm{CG}_{\mathbf{2}}\right.$ TCCTAC) photolysis and combination reaction of $\mathrm{G}(-\mathrm{H})^{\bullet}$ and $\mathrm{O}_{2}{ }^{--}$ radicals. Reversed-phase HPLC elution profile of the oxidation products generated in the (A) absence, and (B) presence of $5 \mu \mathrm{M} \mathrm{Cu}, \mathrm{Zn}-\mathrm{SOD}$. The 5'-d(CAT[ $\left.\mathbf{G}_{\mathbf{1}} \mathbf{P y}_{\mathbf{P}}\right] \mathbf{G}_{\mathbf{2}}$ TCCTAC) oligonucleotides $(100 \mu \mathrm{M})$ in air-equilibrated $5 \mathrm{mM}$ phosphate buffer solution $(\mathrm{pH} 7.5)$ containing $100 \mathrm{mM} \mathrm{NaCl}$ were excited by a $10 \mathrm{~s}$ train of $355 \mathrm{~nm}$ laser pulses $(4 \mathrm{~mJ} / \mathrm{pulse} /$ $\mathrm{cm}^{2}, 10$ pulse/s, dose: $400 \mathrm{~mJ} / \mathrm{cm}^{2}$ ). HPLC elution conditions (detection of products at 260 $\mathrm{nm}): 10-70 \%$ linear gradient of acetonitrile in $50 \mathrm{mM}$ triethylammonium acetate ( $\mathrm{pH} 7$ ) for $60 \mathrm{~min}$ at a flow rate of $1 \mathrm{~mL} / \mathrm{min}$. The parent sequence 5'-d(CAT[ $\left.\mathbf{G}_{\mathbf{1}}{ }^{\mathbf{P y}}\right] \mathrm{CG}_{\mathbf{2}}$ TCCTAC) elutes 
at $~ 28 \mathrm{~min}$ (4), the imidazolone adducts at $26 \mathrm{~min}(3)$, and the $\mathrm{M}+16$ adducts at $22 \mathrm{~min}$ (1) and $24 \mathrm{~min}$ (2). (C) Kinetics of the combination reaction of G(-H) ${ }^{\bullet}$ and $\mathrm{O}_{2}{ }^{--}$radicals, monitored at $315 \mathrm{~nm}$, after excitation of the $5^{\prime}-\mathrm{d}\left(\mathrm{CAT}_{[} \mathbf{G}_{\mathbf{1}} \mathbf{P y}^{\mathbf{P y}}\right] \mathbf{C G}_{\mathbf{2}}$ TCCTAC) sequence with single $355 \mathrm{~nm}$ laser pulses $\left(38 \mathrm{~mJ} /\right.$ pulse/ $\left./ \mathrm{cm}^{2}\right)$ in the absence and the presence of $5 \mu \mathrm{M} \mathrm{Cu}, \mathrm{Zn}-\mathrm{SOD}$. 


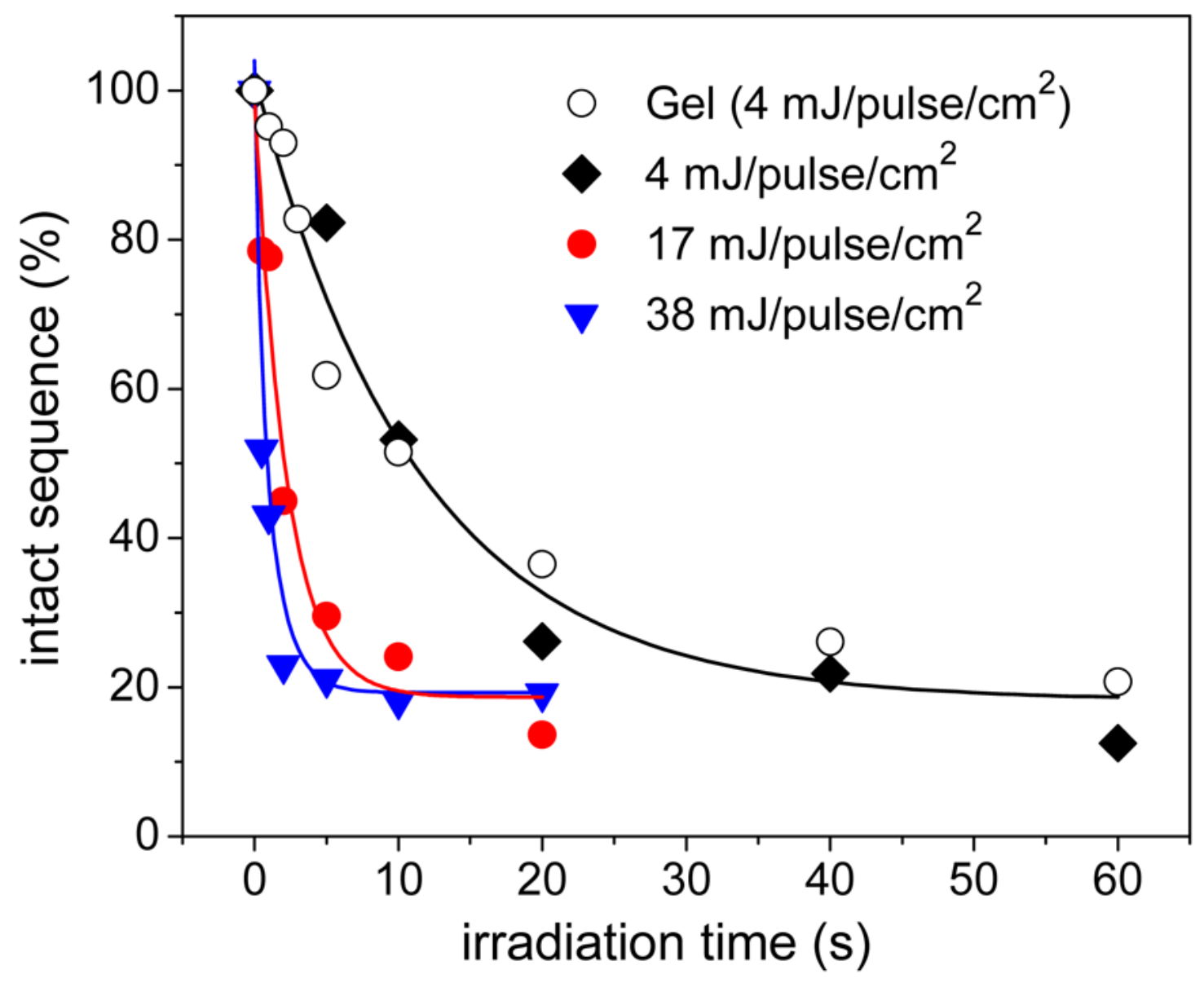

Figure 4.

Photodamage of the 5'-d(CAT[ $\left.\mathbf{G}_{\mathbf{1}} \mathbf{P y}^{\mathbf{P y}}\right] \mathbf{C G}_{\mathbf{2}}$ TCCTAC) single-stranded oligonucleotide induced by $355 \mathrm{~nm}$ laser flashes (10 pulses/sec) in air-equilibrated $5 \mathrm{mM}$ phosphate buffer solution $(\mathrm{pH}$ 7.5) containing $100 \mathrm{mM} \mathrm{NaCl}$ and monitored by reversed-phase HPLC. The fractions of uncleaved oligonucleotides were estimated by integration of the areas under the trace defining the retention time of the undamaged 5'-d(CAT $\left[\mathbf{G}_{\mathbf{1}} \mathbf{P y}^{\mathbf{P}}\right] \mathbf{C G}_{\mathbf{2}}$ TCCTAC) sequence in the relevant HPLC elution profiles, and compared with the results obtained by gel electrophoresis. 

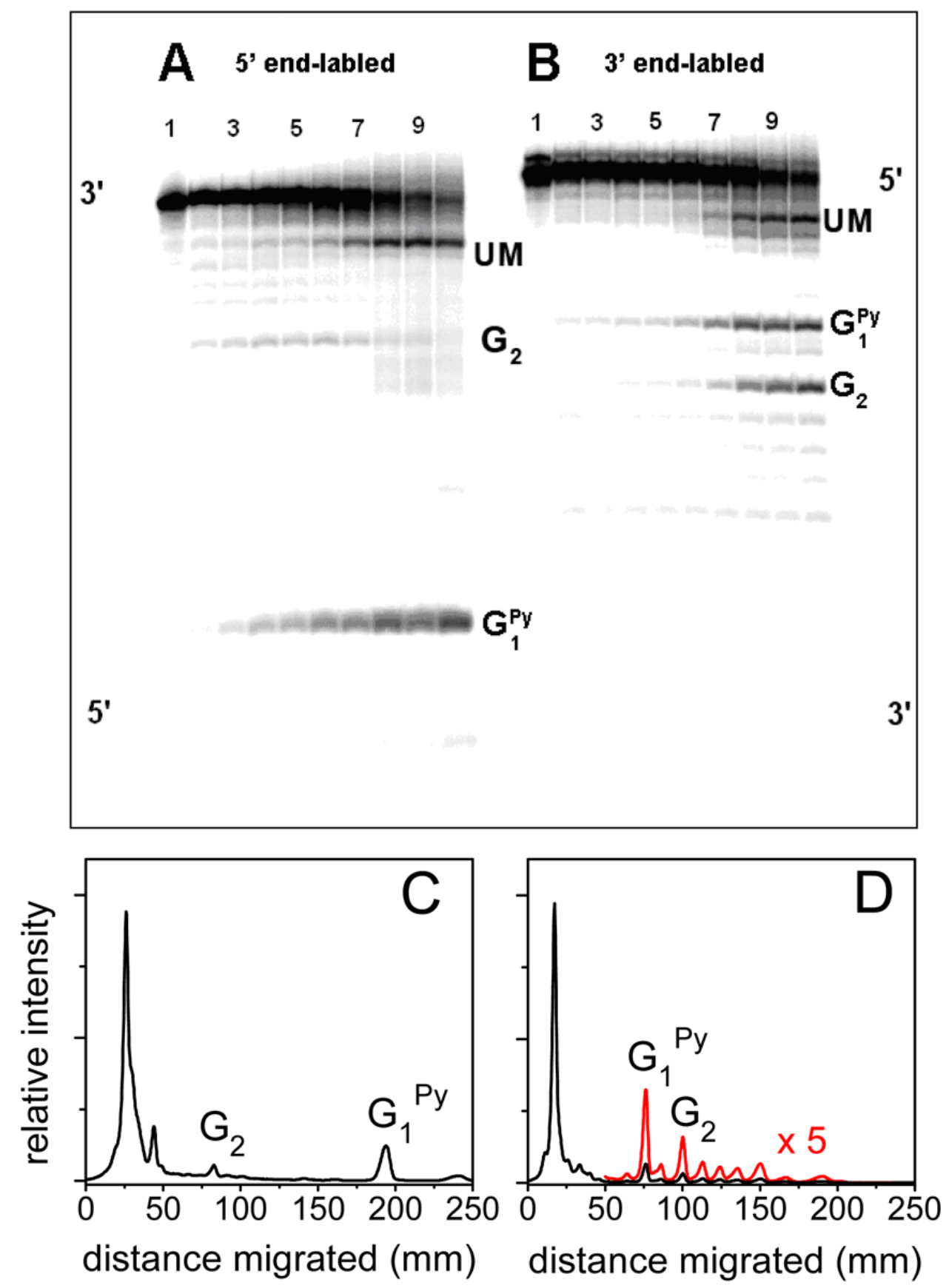

Figure 5.

Autoradiographs of denaturating gels (7 M urea, 20\% polyacrylamide gel) showing the cleavage patterns of the 5'-d(CAT[ $\left.\mathbf{G}_{\mathbf{1}} \mathbf{P y}^{\mathbf{P}}\right] \mathbf{C G}_{\mathbf{2}}$ TCCTAC) single-stranded oligonucleotide labeled either at their 5'-termini (A) or 3'-termini (B), and excited by $355 \mathrm{~nm}$ laser pulses (4 $\mathrm{mJ} / \mathrm{pulse} / \mathrm{cm}^{2}, 10 \mathrm{pulse} / \mathrm{s}$ ) for different time intervals. Lane 1: Unirradiated sequence (without piperidine treatment); Lane 2: Unirradiated sequence (after hot piperidine treatment); Lanes 3 - 10: Irradiated sequence (after hot piperidine treatment) irradiated for 1, 2, 3, 5, 10, 20, 40 and $60 \mathrm{~s}$. The bottom panels (C and $\mathrm{D})$ show examples of histograms obtained by scanning the original autoradiograms A (lane 7) and B (lane 7), respectively. The positions of the fragment 
arising from cleavage at the indicated guanines were ascertained from standard Maxam-Gilbert reactions (Supporting Information; UM: unmodified 12-mer sequence). 

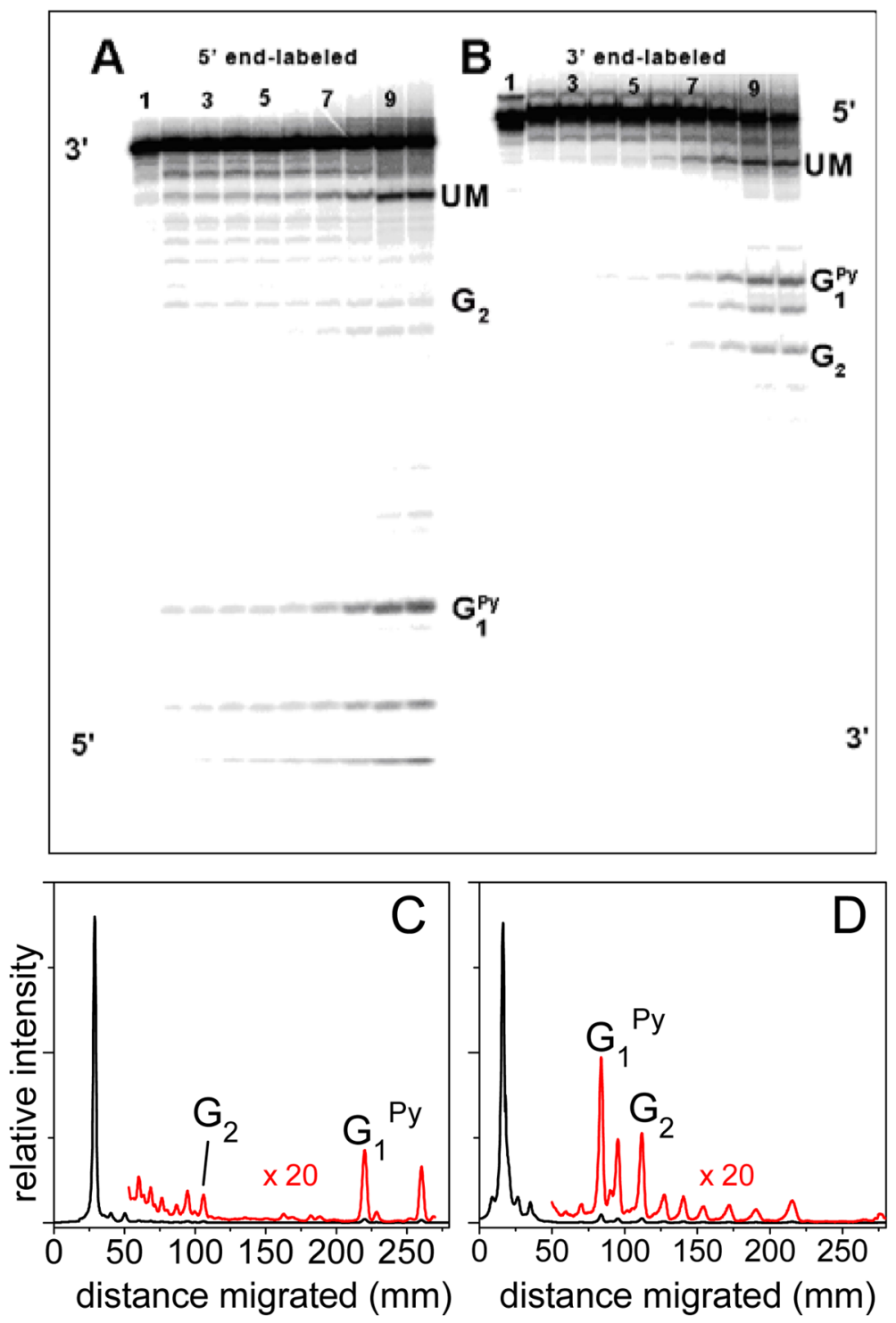

Figure 6.

Autoradiograph of a denaturating gel (7 M urea, 20\% polyacrylamide gel) showing the cleavage patterns of the 5'-d(CAT[ $\left.\mathbf{G}_{\mathbf{1}} \mathbf{P y}\right] \mathbf{C G}_{\mathbf{2}}$ TCCTAC) double-stranded oligonucleotide labeled either at their $5^{\prime}$ or $3^{\prime}$-termini and excited by a $10 \mathrm{~s}$ train of $355 \mathrm{~nm}$ laser pulses $\left(4 \mathrm{~mJ} / \mathrm{pulse} / \mathrm{cm}^{2}, 10\right.$ pulse/s) for different time intervals. Lane 1: Unirradiated duplex (without piperidine treatment); Lane 2: Unirradiated duplex (after hot piperidine treatment); Lanes 3-10: Irradiated sequence (after hot piperidine treatment) irradiated by 1, 2, 3, 5, 10, 20, 40 and 60 s. The bottom panels show the histograms $\mathrm{C}$ and $\mathrm{D}$ obtained by scanning the original autoradiograms A (lane 7) and B (lane 7), respectively. Labels are in Figure 5. 

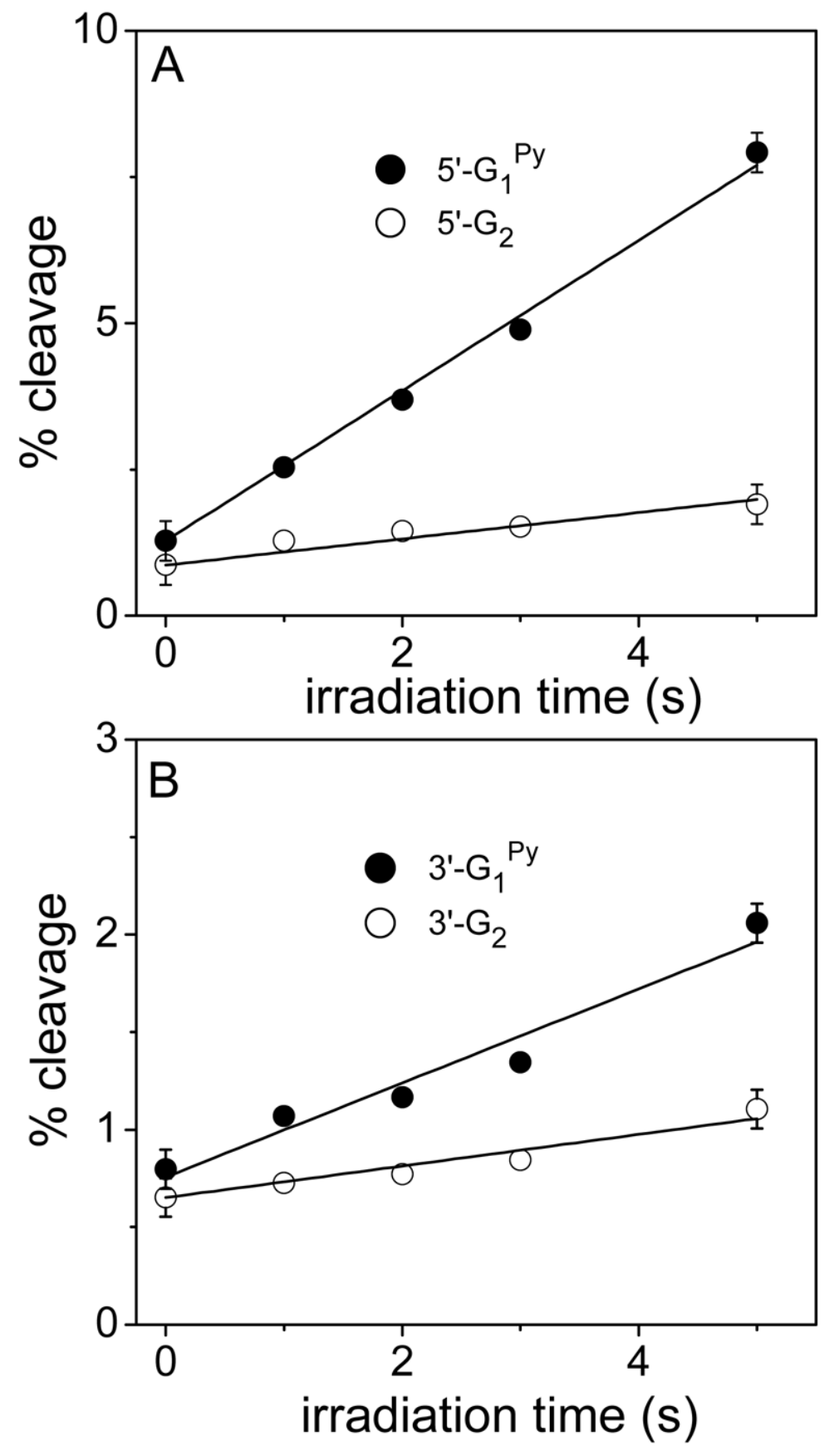

Figure 7.

Kinetics of photodamage formation at guanine sites in the $5^{\prime}-\mathrm{d}\left(\mathrm{CAT}\left[\mathbf{G}_{\mathbf{1}} \mathbf{P y}_{\mathbf{C}}\right] \mathbf{C G}_{\mathbf{2}}\right.$ TCCTAC) single-stranded oligonucleotide induced by $355 \mathrm{~nm}$ laser pulses (4 mJ/pulse/cm $\left.{ }^{2}, 10 \mathrm{pulse} / \mathrm{s}\right)$. The percent cleavage was calculated by integration of the histograms obtained by scanning the original autoradiograms shown in Figure 5. 

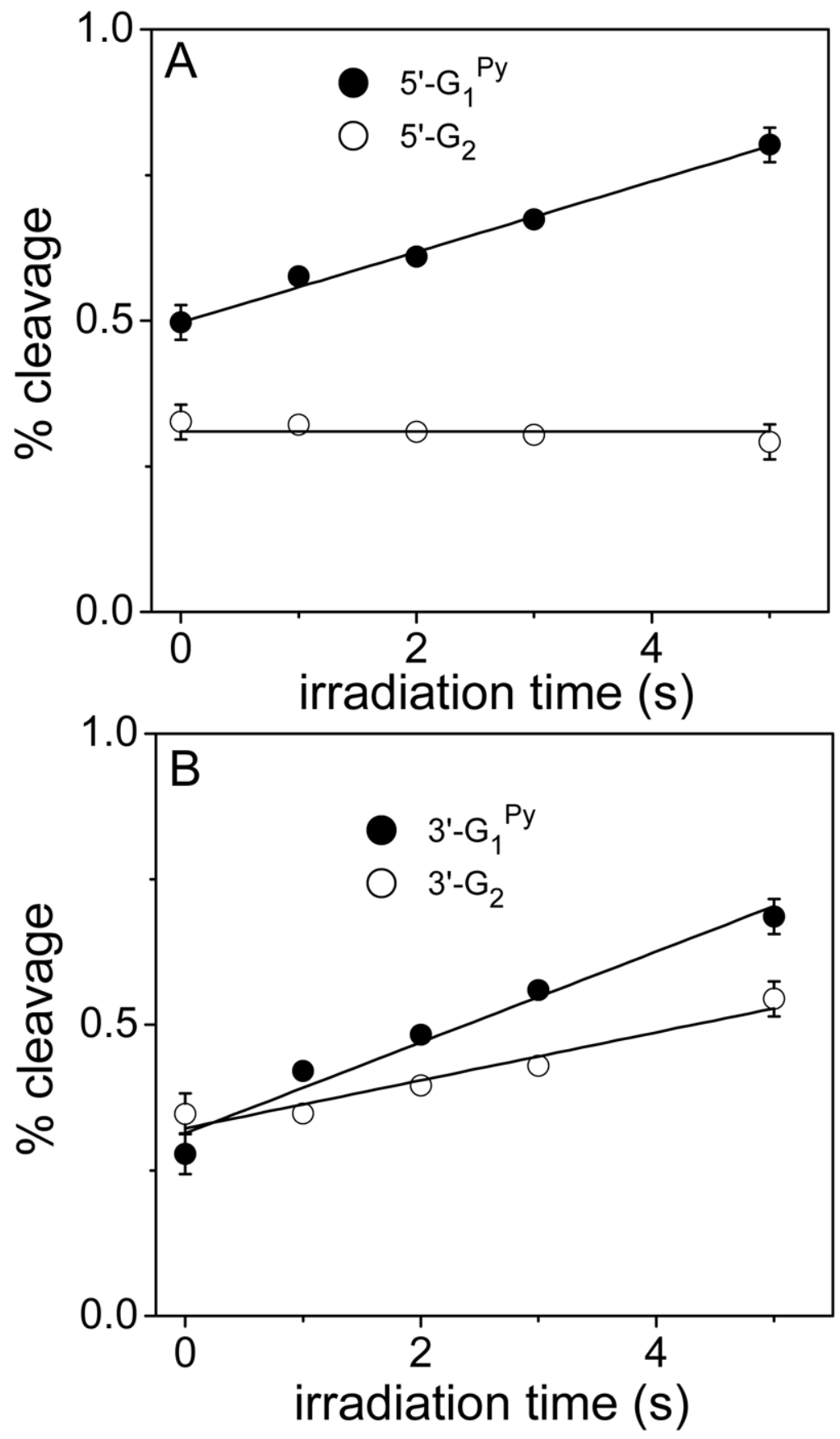

Figure 8.

Kinetics of photodamage at guanine sites in the sequence $5^{\prime}-\mathrm{d}\left(\mathrm{CAT}\left[\mathrm{G}_{1}{ }^{\mathrm{Py}}\right] \mathrm{CG}_{\mathbf{2}}\right.$ TCCTAC) in the double-stranded form induced by $355 \mathrm{~nm}$ laser pulses $\left(4 \mathrm{~mJ} / \mathrm{pulse} / \mathrm{cm}^{2}, 10 \mathrm{pulse} / \mathrm{s}\right)$. The percent of the cleavage was calculated by integration of the histograms obtained by scanning the original autoradiograms shown in Figure 6. 


$$
\begin{aligned}
& \text { 5'- } \quad \text { C A } \\
& \text { 3'- T G } G_{7} T A \quad C \quad G_{6} C \quad A G_{5} G_{4} \text { A T G } G_{3} T-5^{\prime 32} P
\end{aligned}
$$

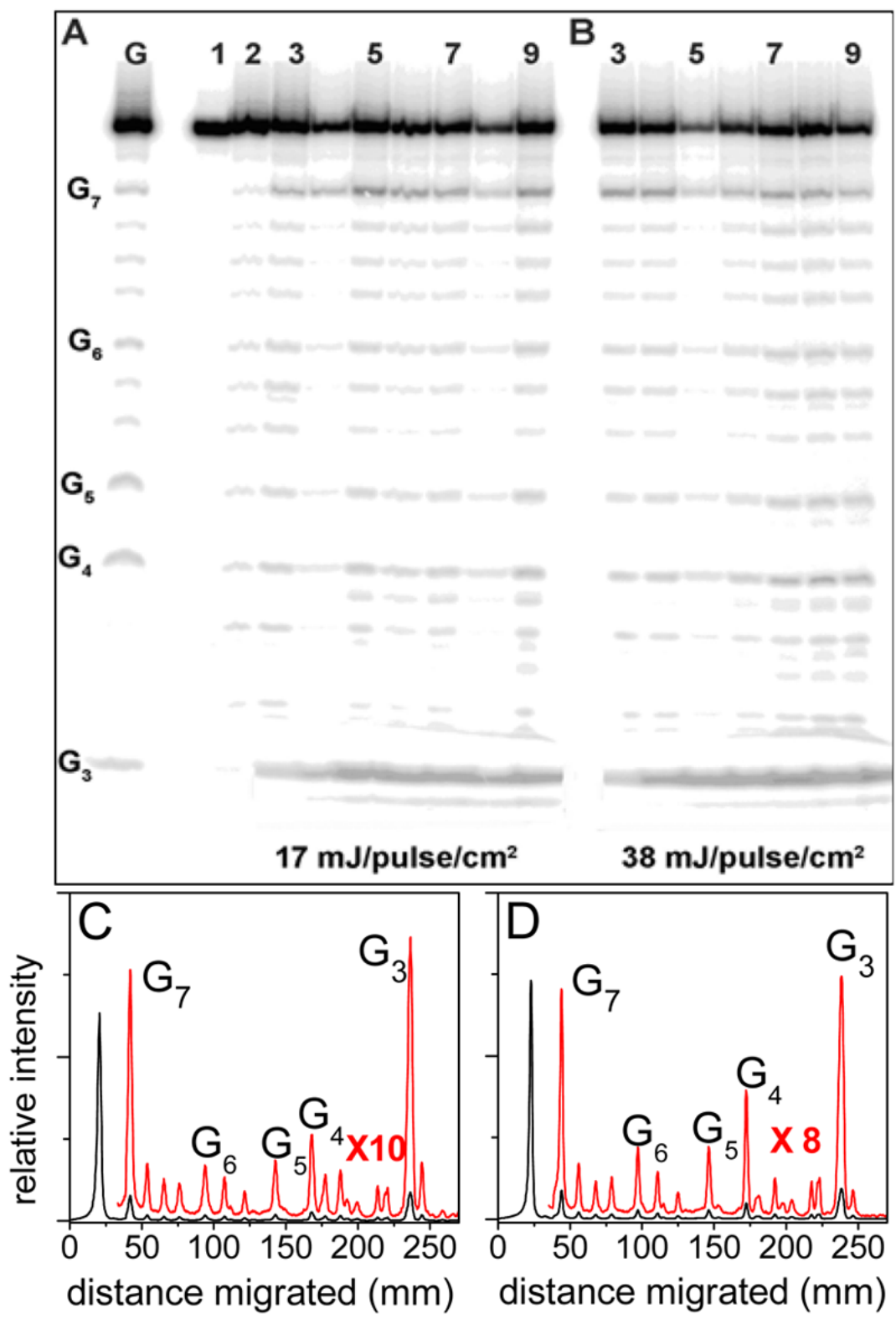

Figure 9.

Autoradiograph of a denaturating gel ( $7 \mathrm{M}$ urea, $20 \%$ polyacrylamide gel) showing the cleavage patterns of the $5^{\prime}-\mathrm{d}\left(\mathrm{TG}_{3} \mathrm{TAG}_{4} \mathrm{G}_{5} \mathrm{ACG}_{6} \mathrm{CATG}_{7} \mathrm{~T}\right)$ complementary strands $32 \mathrm{P}$-endlabeled at their $5^{\prime}$-termini and excited by a $10 \mathrm{~s}$ train of $355 \mathrm{~nm}$ laser pulses $\left(4 \mathrm{~mJ} /\right.$ pulse $/ \mathrm{cm}^{2}, 10 \mathrm{pulse} /$ s) in the double-stranded form. Lane 1: Unirradiated duplex (without piperidine treatment); Lane 2: Unirradiated duplex (after hot piperidine treatment); Lanes 3 - 10: Irradiated sequence (after hot piperidine treatment) irradiated for 1, 2, 3, 5, 10, 20, 40 and $60 \mathrm{~s}$. The bottom panels show the histograms $\mathrm{C}$ and $\mathrm{D}$ obtained by scanning the original autoradiograms A: lane 8 (17 $\mathrm{mJ} /$ pulse $/ \mathrm{cm}^{2}, 40 \mathrm{~s}$, dose: $\left.6.8 \times 10^{3} \mathrm{~mJ} / \mathrm{cm}^{2}\right)$, and B: lane $8\left(38 \mathrm{~mJ} / \mathrm{pulse} / \mathrm{cm}^{2}, 40 \mathrm{~s}\right.$, dose: $15.2 \times 10^{3} \mathrm{~mJ} / \mathrm{cm}^{2}$, respectively). 


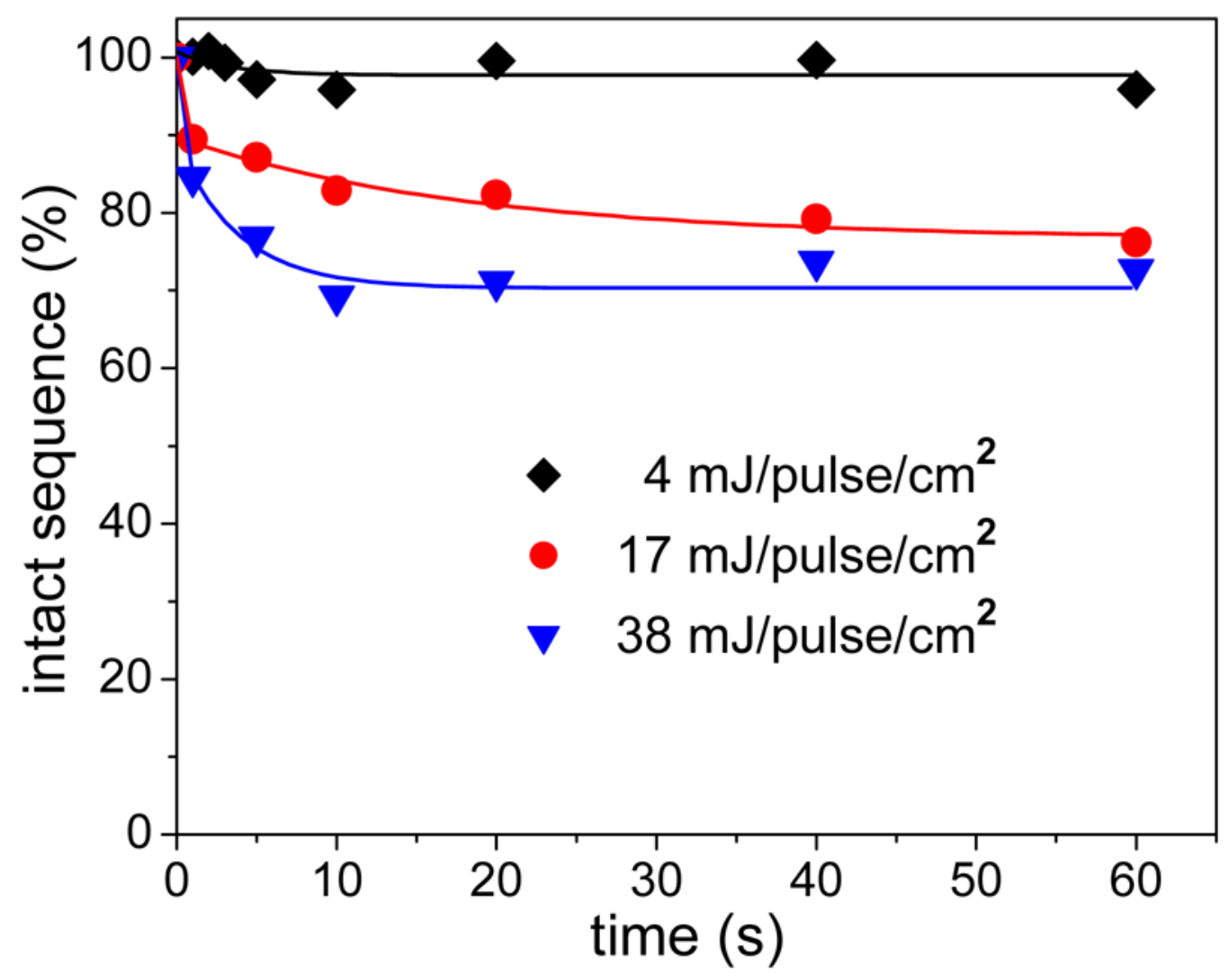

Figure 10.

Photodamage of the unmodified $5^{\prime}-\mathrm{d}\left(\mathrm{TG}_{3} \mathrm{TAG}_{4} \mathrm{G}_{5} \mathrm{ACG}_{6} \mathrm{CATG}_{7} \mathrm{~T}\right)$ complementary strand in the duplex with the modified strand 5'-d(CAT $\left[\mathbf{G}_{\mathbf{1}} \mathbf{P y}_{\mathbf{y}}\right] \mathbf{C G}_{\mathbf{2}}$ TCCTAC) induced by $355 \mathrm{~nm}$ laser flashes. The fraction of cleaved complementary DNA strands was calculated by integration of the histograms obtained by scanning the original autoradiograms shown in Figure 9. 